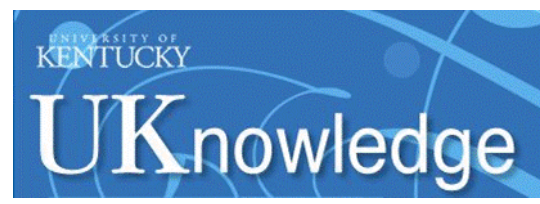

University of Kentucky

UKnowledge

\title{
Role of Phosphoinositide 3-Kinase - Akt Signaling Pathway in the Age-Related Cytokine Dysregulation in Splenic Macrophages Stimulated via TLR-2 or TLR-4 Receptors
}

\author{
Mosoka Papa Fallah \\ University of Kentucky, mosoka.fallah@uky.edu \\ R. Lakshman Chelvarajan \\ University of Kentucky, RCHEL1@uky.edu \\ Beth A. Garvy \\ University of Kentucky, beth.garvy@uky.edu \\ Subbarao Bondada \\ University of Kentucky, bondada@uky.edu
}

Follow this and additional works at: https://uknowledge.uky.edu/microbio_facpub

Part of the Medical Immunology Commons, Medical Microbiology Commons, and the Molecular Genetics Commons

Right click to open a feedback form in a new tab to let us know how this document benefits you.

\section{Repository Citation}

Fallah, Mosoka Papa; Chelvarajan, R. Lakshman; Garvy, Beth A.; and Bondada, Subbarao, "Role of Phosphoinositide 3-Kinase - Akt Signaling Pathway in the Age-Related Cytokine Dysregulation in Splenic Macrophages Stimulated via TLR-2 or TLR-4 Receptors" (2011). Microbiology, Immunology, and Molecular Genetics Faculty Publications. 126.

https://uknowledge.uky.edu/microbio_facpub/126

This Article is brought to you for free and open access by the Microbiology, Immunology, and Molecular Genetics at UKnowledge. It has been accepted for inclusion in Microbiology, Immunology, and Molecular Genetics Faculty Publications by an authorized administrator of UKnowledge. For more information, please contact UKnowledge@lsv.uky.edu. 
Role of Phosphoinositide 3-Kinase - Akt Signaling Pathway in the Age-Related Cytokine Dysregulation in Splenic Macrophages Stimulated via TLR-2 or TLR-4 Receptors

Digital Object Identifier (DOI)

https://doi.org/10.1016/j.mad.2011.05.003

Notes/Citation Information

Published in Mechanisms of Ageing and Development, v. 132, issues 6-7, p. 274-286.

Copyright $@ 2011$ Elsevier Ireland Ltd. All rights reserved.

This manuscript version is made available under the CC-BY-NC-ND 4.0 license http://creativecommons.org/licenses/by-nc-nd/4.0/.

The document available for download is the author's post-peer-review final draft of the article. 


\title{
Role of phosphoinositide 3-kinase - Akt signaling pathway in the age-related cytokine dysregulation in splenic macrophages stimulated via TLR2 or TLR 4 receptors
}

\author{
Mosoka P. Fallah ${ }^{\mathrm{a}, \mathrm{b}}$, R. Lakshman Chelvarajan ${ }^{\mathrm{a}, \mathrm{b}}$, Beth A. Garvy ${ }^{\mathrm{a}}$, and Subbarao \\ Bondada ${ }^{a, b,{ }^{*}}$ \\ aDepartment of Microbiology, Immunology and Molecular Genetics University of Kentucky \\ College of Medicine, Lexington, KY 40536 USA \\ bMarkey Cancer Center, University of Kentucky College of Medicine, Lexington, KY 40536 USA
}

\section{Abstract}

\begin{abstract}
Age-associated defects in both B-lymphocytes and macrophages in elderly result in a reduction in the efficacy of vaccines to many Gram positive bacteria like Streptococcus pneumoniae. Splenic macrophages from aged mice have been shown to have a defect in production of pro-inflammatory cytokines (IL-6, IL-12, IL-1 $\beta$, TNF- $\alpha$ ) but exhibit increased production of IL-10 upon TLR4 ligation. Here we showed that aged macrophages demonstrate similar cytokine dysregulation phenotype upon stimulation with TLR2 ligands, or killed S. pneumoniae. We hypothesized that an age-associated increase in activity of phosphatidyl inositol 3-kinase (PI3K)-Akt signaling pathway may be playing a causal role in the age-associated cytokine dysregulation. We found that gene

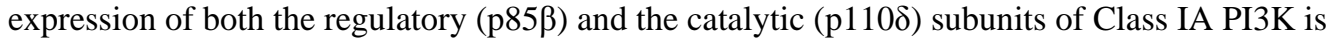
higher in aged than in young splenic macrophages. The age-associated increase in the activity of PI3K was also demonstrated by an upregulation of P-Akt and its downstream target, glycogen synthase kinase-3 (GSK-3). Inhibition of PI3K enhanced induction of pro-inflammatory cytokines, by TLR-2/TLR-1, TLR-2/TLR-6 and TLR-4 ligands as well as heat killed $S$. pneumoniae (HKSP). Therefore, targeting PI3-Kinase could rescue cytokine dysregulation in aged macrophages and enhance the relevant pro-inflammatory cytokines needed to support B-cell activation and differentiation.
\end{abstract}

\section{Keywords}

Aging; Toll-Like receptors; Streptococcus pneumonia; phosphatidyl inosital 3-kinase (PI3K); macrophages

\section{Introduction}

Numerous studies have established the senescence of the immune system in aged human and murine populations resulting in reduced effectiveness of both the innate and the acquired

(C) 2011 Elsevier Ireland Ltd. All rights reserved.

*Corresponding author: Subbarao Bondada, Department of Microbiology, Immunology and Molecular Genetics, University of Kentucky College of Medicine, 303 Combs Cancer Building, Lexington, KY, 40536-0096, Phone: (859) 323-4705 Fax: (859) 257-8940bondada@uky.edu .

Publisher's Disclaimer: This is a PDF file of an unedited manuscript that has been accepted for publication. As a service to our customers we are providing this early version of the manuscript. The manuscript will undergo copyediting, typesetting, and review of the resulting proof before it is published in its final citable form. Please note that during the production process errors may be discovered which could affect the content, and all legal disclaimers that apply to the journal pertain. 
arms of the immune system of the elderly. As a result, older individuals are more susceptible to infections, particularly with Gram positive bacteria such as S. pneumoniae and consistently demonstrate an impaired immune response to pneumococcal polysaccharide vaccine (Jackson \& Janoff, 2008; Lynch \& Zhanel, 2009, 2010; Romero-Steiner, et al., 1999).

S. pneumoniae bacteria have a polysaccharide capsule, which contains structures like lipoteichoic acid and lipoprotein that activate TLR-2 signaling in macrophages resulting in secretion of both pro-inflammatory and anti-inflammatory cytokines. Effective production of these cytokines by splenic macrophages is known to provide the second signal needed for B-cell anti-capsular polysaccharide antibody response (Bondada, Wu, Robertson, \& Chelvarajan, 2000; Khan, Shen, Wu, Wynn, \& Snapper, 2002). The first signal is provided by the repetitive epitopes of the capsular polysaccharide (Bondada, et al., 2000). During the progression of infection, pneumolysin, another component of S. pneumoniae is released and engages TLR-4 resulting in massive chronic inflammation and sepsis that are associated with pneumococcal pneumonia (Dessing, Hirst, de Vos, \& van der Poll, 2009; Malley, et al., 2003). Secreted cytokines like IL-12 and IL-6 have been shown to help B-cells to produce increased $\operatorname{IgG}_{3}$ or $\mathrm{IgA}$ in the absence of help from T-cells (Arulanandam, Lynch, Briles, Hollingshead, \& Metzger, 2001; Bondada, et al., 2000; R. L. Chelvarajan, Gilbert, \& Bondada, 1998; Khan, et al., 2002; Metzger, et al., 1996). Both $\operatorname{IgA}$ and $\mathrm{IgG}_{3}$ promote opsonization of the bacteria. TNF- $\alpha$ is another pro-inflammatory cytokine that is produced by $S$. pneumoniae activated macrophages and also aids in the recruitment of neutrophils and macrophages, which phagocytose the opsonized bacteria (Kerr, et al., 2002; Lee, Scanga, Bachelder, Chen, \& Snapper, 2007).

We have previously shown that upon stimulation with LPS, a TLR-4 ligand, aged splenic macrophages secrete lower levels of the pro-inflammatory cytokines, IL-6, IL-12, and TNF$\alpha$, but higher levels of IL-10, resulting in cytokine dysregulation (L. Chelvarajan, et al., 2007; R. L. Chelvarajan, Collins, Van Willigen, \& Bondada, 2005; R. L. Chelvarajan, et al., 2006). Similar defects in TLR-induced pro-inflammatory cytokine secretion by aged splenic macrophages have also been observed in other studies (Boehmer, Goral, Faunce, \& Kovacs, 2004; Renshaw, et al., 2002). As a result, TLR-4 activated aged macrophages or their secreted pro-inflammatory cytokines are not able to effectively provide support to B-cell mediated anti-capsular polysaccharide antibody responses (Bondada, et al., 2000; Garg, Luo, Kaplan, \& Bondada, 1996). Here we investigated whether or not similar cytokine dysregulation is exhibited when aged macropahges are stimulated with different types of TLR-2 ligands that are relevant in the context of pneumococcal infections. Unlike other TLRs that form homodimers, the TLR-2 receptor complex is a heterodimer which gives it the ability to recognize a broader spectrum of ligands. Gram positive bacteria contain lipoproteins that are known to be recognized by TLR-2 resulting in the initiation of inflammation and control of bacterial infection (Santos-Sierra, et al., 2009). We also investigated this phenomenon in the context of heat killed S. pneumoniae (HKSP).

The lipoproteins or lipopeptides derived from them are differentially recognized by either the TLR2/6 heterodimer or the TLR2/1 heterodimer depending on whether the cysteine residue is diacylated or triacylated. TLR2/1 recognizes a variety of bacterial lipopeptide/ lipoproteins including mycobacterial lipoprotein, meningococcal lipoprotein and synthetic Pam3CSK4, while TLR2/6 recognizes mycoplasma lipoprotein, peptidoglycan and the synthetic Pam2CSK4. (Takeuchi, et al., 2001; Wetzler, 2003). However, some studies have shown that TLR-2 can recognize some bacterial ligands such as lipoteichoic acids (LTA) independent of TLR-1 or 6 (Buwitt-Beckmann, et al., 2006). LTAs are more restricted to Gram positive bacteria than synthetic Pam2CSK4 and Pam3CSK4 like lipopeptides that can be found in both Gram positive and Gram negative bacteria (Han, Kim, Martin, Michalek, \& 
Nahm, 2003; Seo, Michalek, \& Nahm, 2008). LTA is a potent inducer of inflammatory cytokines in macrophages and human PBMC and is important for innate responses to Gram positive bacteria (Farhat, et al., 2008; Seo, et al., 2008; Wetzler, 2003).

In spite of the critical role of phosphatidyl inositol-3 kinase (PI3K) in modulating proinflammatory and anti-inflammatory cytokines in macrophages and dendritic cells (DC), little research has been done to investigate age-related changes in this important signaling molecule and its potential therapeutic value (Katso, et al., 2001; Marone, Cmiljanovic, Giese, \& Wymann, 2008). PI3K enzymes form a group of lipid kinases consisting of Class I, II and III that are involved in diverse cellular processes including cell growth, migration, apoptosis, proliferation, chemotaxis, and differentiation among others. The Class I PI3K generally catalyzes the phosphorylation of the phosphoinositide at the $\mathrm{D} 3$ position and thus converts PtdIns $(4,5) \mathrm{P}_{2}\left(\mathrm{PIP}_{2}\right)$ to PtdIns $(3,4,5) \mathrm{P}_{3}\left(\mathrm{PIP}_{3}\right)$ (Katso, et al., 2001; Marone, et al., 2008). The Class I PI3K enzymes can be divided further into Class IA and IB isoforms. The Class IA PI3K consists of a regulatory subunit (p85, p55) and a catalytic subunit (p110) and is activated via a tyrosine-kinase coupled receptor. The regulatory subunit is first recruited to the tyrosine phosphorylated residues in the plasma membrane via its SH-2 domain. It then recruits the catalytic domain to the plasma membrane, stabilizes it and brings it in close proximity to its lipid substrate. The Class IB PI3K catalytic subunit lacks the $\mathrm{p} 85$ binding domain and is activated by G protein coupled receptors, (Katso, et al., 2001; Marone, et al., 2008). The levels of PIP3 can be down-modulated by PTEN (phosphatase and tensin homolog) and SHIP (Src-homology-2 containing inositol 5'-phosphatase), which are phosphatases that respectively target the D3 and D5 position of PIP3 converting it to PIP2 (Marone, et al., 2008). The PIP3 generated by PI3K activity serves as a docking site for the recruitment of signaling proteins via their pleckstrin homology domains. One of the kinases that is recruited to the membrane by PIP3 is the phosphoinositide-dependent kinase-1 (PDK-1), which then targets the serine-threonine kinase, Akt for phosphorylation at Thr-308 (Cen, et al., 2007). The activated Akt serves as a master kinase for a plethora of downstream substrates including IKK and GSK-3 (Katso, et al., 2001).

Recent studies have shown that PI3K signaling also plays a role in most TLR signaling as inhibition of PI3K with pharmacological inhibitors results in differential regulation of antiand pro-inflammatory cytokines (Fukao \& Koyasu, 2003; Martin, et al., 2003; Saegusa, Yotsumoto, Kato, \& Aramaki, 2007). In addition, it has been shown that the Class IA PI3K are activated after stimulation via diverse TLRs such as TLR2, TLR3,TLR4, TLR5, TLR9 and also the IL-1R signaling pathway (Fukao \& Koyasu, 2003). However, the connection between the TLR signaling and PI3K has only been recently elucidated in gene knockout studies (Luyendyk, et al., 2008). It has been shown that MyD88 directly interacts with the p85 subunit of PI3K (Laird, et al., 2009). The PI3K pathway is known to negatively regulate the TLR induced production of pro-inflammatory cytokines (Fukao \& Koyasu, 2003; Martin, et al., 2003; Pengal, et al., 2006; Saegusa, et al., 2007). Moreover, there is some evidence that this pathway is required for IL-10 production (Polumuri, Toshchakov, \& Vogel, 2007; Saegusa, et al., 2007). Hence, we questioned if PI3K levels were elevated with aging and if inhibiting PI3K in aged splenic macrophages could restore the production of pro-inflammatory cytokines upon stimulation with either TLR ligands or HKSP. We discovered that there was an age-associated increase in the amount of PI3K subunit specific mRNA and its activity as shown by increased phosphorylation of AKT and GSK-3. Inhibition of the PI3K-AKT signaling pathway enhanced TLR2 and HKSP induced proinflammatory cytokines and decreased the anti-inflammatory cytokine levels in both the aged and young adult macrophages, suggesting that modulators of PI3K pathway may engender better immune responses in the aged to infections with bacteria such as pneumococci that express TLR2 ligands. 


\section{Materials and methods}

\subsection{ANIMALS}

Female young (8-12 weeks old) and aged (18-22 months old) Balb/c mice were obtained from the National Institute of Aging (NIA), National Institute of Health (NIH, Bethesda, $\mathrm{MD})$. The mice were kept in the facility at the Department of Laboratory Animal Research (DLAR) at our university on a $12 \mathrm{~h}$ daylight and $12 \mathrm{~h}$ night cycle and given food and water ad libitum. The protocols involving the animals were approved by the University of Kentucky Institutional Animal Care and Use Committee.

\subsection{REAGENTS}

The TLR-4 agonist LPS (Escherichia coli 055:B5) and the TLR-2 ligands, Pam-3-CSK4 and the GSK-3 inhibitor, SB216763 were obtained from Sigma Chemical Co. (St. Louis, MO), whereas the TLR-2 ligands, Pam-2-CSK4 and Lipoteichoic acid were obtained from In Vivogen (San Diego, CA). LY294002 and wortmannin, the inhibitors for PI3K were obtained from Calbiochem (San Diego, CA). FITC- conjugated anti-mouse LY-6G and antiCD5 were obtained from BioLegend (San Diego, CA), while the FITC-conjugated antimouse CD45R (B220) was obtained from eBioSciences (San Diego, CA). The anti-FITC microbeads were obtained from Miltenyi Biotec (Auburn, CA). Serotype-2 S. pneumoniae bacteria were grown on blood agar plates and were inactivated by $10 \%$ formalin or heat treatment at $60^{\circ} \mathrm{C}$ for 1 hour. The OptEIA TMB peroxidase substrate for the ELISA was acquired from BD Biosciences (San Diego, CA).

\subsection{CELL REPARATION}

Mice were euthanized via carbon dioxide asphyxiation and the spleens aseptically removed and crushed into a single cell suspension. After washing and erythrocyte lysis, the Fc $\gamma \mathrm{R}$ were blocked with normal rat IgG for 15 minutes. The splenocytes were then incubated with a cocktail of FITC conjugated monoclonal antibodies against B220, CD5 and Ly6G in the dark for 30 minutes. This was followed by washing with MACS buffer and incubation with anti-FITC microbeads at $4-8^{\circ} \mathrm{C}$ for 15 minutes. The purified macrophages were obtained by separating the magnetic bead bound and unbound cells using the Miltenyi AUTOMACS Cell Separator. The resulting untouched macrophages were found to be 90-95\% F4-80 positive cells. The purified macrophages were cultured in RPMI complete $+10 \%$ fetal calf serum (FCS) at $37^{\circ} \mathrm{C}$ in a humidified $5 \% \mathrm{CO}_{2}$ atmosphere.

\subsection{FLOW CYTOMETRIC ANALYSIS FOR MACROPHAGE CELL SURFACE STAINING}

Control and LPS $(1 \mu \mathrm{g} / \mathrm{ml})$ or Pam-3-CSK4 $(1 \mu \mathrm{g} / \mathrm{ml})$, Pam-2-CSK4 $(1 \mu \mathrm{g} / \mathrm{ml})$ as well as LTA $(1 \mu \mathrm{g} / \mathrm{ml})$ stimulated splenic macrophages were cultured for 24 hours and gently removed by scraping them off the plate. These macrophages from the aged and the young mice were stained for surface expression of CD86 and F4/80 using directly conjugated flourochrome antibodies (BD Pharmingen) for 30 minutes on ice. The cell fluorescence was analyzed by analyzing 10,000 events after gating for viable cells based on forward light scatter and side scatter, using the FACS CALIBUR (BD Instruments, San Jose, CA).

\subsection{CYTOKINE ELISA}

Cell free supernatants from either basal or activated purified splenic macrophages $\left(2.5 \times 10^{5}\right.$ cells $/ \mathrm{ml}$ ) were harvested following culture with or without TLR ligands or heat killed $S$. pneumoniae for 24 hours. TLR ligands were tested at different concentrations and the optimal dose determined was then used in all experiments. The supernatants were assayed for cytokines, IL-10, IL-12(p40), IL-12(p70), IL-6 and TNF- $\alpha$, by ELISA using OptEIA kits (BD Biosciences, San Diego, CA). The optical densities (OD) were read on an HTS 7000 
plate reader (Perkin Elmer, Norwalk, CT). The results were expressed as mean $+/-\mathrm{SE}$ of triplicate determinations of supernatants from duplicate cultures.

\subsection{WESTERN BLOT}

The splenic macrophages from aged and young adult Balb/c mice were plated at $2 \times 10^{6}$ cells/well in $500 \mu 1$ of RPMI $1640+2 \%$ FCS in 24 well tissue culture plates. These cells are allowed to rest for 4 hours to allow macrophage adherence and recovery from handling and then stimulated with $1 \mu \mathrm{g} / \mathrm{ml}$ LPS or Pam-3-CSK4, for 15 or 30 minutes. These time points and doses were chosen after performing a detailed kinetic analysis. For inhibition of PI3 kinase pathway, macrophages were pretreated with wortmannin or LY using doses that were predetermined to be optimal. The reaction was stopped by adding $1.0 \mathrm{ml}$ of ice cold $1 \times$ phosphate buffered saline (PBS). The cells were washed twice with $1.0 \mathrm{ml} 1 \times$ PBS. The macrophages were then lysed in a lysis buffer (Cell Signaling Technologies, Beverly, MA), to which was added protease inhibitor cocktail and phenyl methyl sulfonyl fluoride (Sigma Chemical Co. St. Louis, MO). The total protein content of the sample was determined by BCA protein assay (Pierce, Rockford, IL). Equal amounts of protein were separated by electrophoresis on sodium dodecyl sulfate-polyacrylamide gels (SDS-PAGE) and were transferred to nitrocellulose membranes for Western blot analyses. The membranes were blocked with 2\% FCS and were then probed with the antibodies to p-Akt (S473), AKT, pGSK-3 $\alpha \beta$ and GSK-3, all of which were from Cell Signaling Technologies; PTEN and $\beta$ actin from Santa Cruz Biotechnology (Santa Cruz, CA). The immunoreactive proteins were then detected using horseradish peroxidase coupled secondary antibodies and the PICO Chemiluminescence substrate (Pierce Technology) and by exposing to Kodak X-omat film. The relative OD of the protein bands was estimated using the Kodak Image Station software (Eastman Kodak, New Haven, CT). Band intensities were determined by dividing the phosphorylated protein by the total protein. The blots were stripped with stripping buffer (62.5mM Tris, PH6.8, 2\%SDS, 0.1M 2-mercoptoethanol) and then probed with anti-beta actin (Sigma, St. Louis, MO) to correct for differences in protein loading.

\subsection{REAL-TIME RT-PCR}

Purified splenic macrophages $\left(3 \times 10^{6}\right.$ cells $\left./ 3 \mathrm{ml}\right)$ were stimulated with $1 \mu \mathrm{g} / \mathrm{ml}$ LPS for 30 minutes and RNA extracted by TriZol extraction kit and then reverse transcribed to cDNA using the High Capacity cDNA Archive kit (Applied biosystems, Foster, CA). The cDNA was later amplified by real-time PCR in a $25 \mu \mathrm{L}$ reaction volume containing SYBR Green (QIAGEN, Valencia, CA) and analyzed using an ABI Prism Sequence detection system (Applied Biosystems, Foster City, CA). The experimental cDNA was tested in triplicate and normalized to $18 \mathrm{~S}$ RNA. The RNA levels of p85, p110 and 18S were measured with QuantiTect PCR probes obtained from QIAGEN (Alameda, CA).

\subsection{STATISTICAL ANALYSIS}

Statistical differences between groups were evaluated using an unpaired Student 's $t$ test, or one way ANOVA. In both tests statistical significance was concluded when $\mathrm{p}<0.05$.

\section{RESULTS}

\subsection{Age-associated cytokine dysregulation correlates with an enhancement of Class IA PI3K activity in TLR-4 stimulated macrophages}

We have previously shown that LPS activated aged splenic macrophages exhibited a cytokine dysregulation with a decrease in the pro-inflammatory cytokines but an increase in IL-10, an anti-inflammatory cytokine (R. L. Chelvarajan, et al., 2005). In these experiments macrophages were purified by adherence or by positive selection with anti-CD11b beads. In 
order to establish the role of PI3 kinase in this cytokine dysregulation and to avoid the inadvertent activation of splenic macrophages by either adherence or positive selection with $\mathrm{CD} 11 \mathrm{~b}$ magnetic beads, we purified splenic macrophages using negative selection procedures. This method involved staining splenocytes with anti-CD5-FITC, anti-B220FITC and anti-LY6G and using anti-FITC coupled magnetic beads to remove nonmacrophages. When these negatively selected macrophages from aged mice were stimulated with LPS they showed an increase in IL-10 secretion (Figure 1A) and a decrease in production of pro-inflammatory cytokines, IL-12(p40), IL-6 and TNF- $\alpha$ (Figure 1B) compared to similar cells from young adult mice. Thus these negatively selected macrophages continued to exhibit the same cytokine dysregulation that was observed with macrophages purified by other methods.

We questioned if the observed dysregulation of cytokine secretion by the TLR-4 activated splenic macrophages was due to the differential expression of PI3 kinase Class I isoform of PI3K that is mainly expressed in leukocytes, B-cells, T-cells, macrophages and has been consistently shown to be a negative regulator of pro-inflammatory cytokines upon TLR stimulation (Hazeki, Nigorikawa, \& Hazeki, 2007; Koyasu, 2003; Laird, et al., 2009; Makela, Strengell, Pietila, Osterlund, \& Julkunen, 2009; Saegusa, et al., 2007). Hence, we examined our previously published microarray data (R. L. Chelvarajan, et al., 2006) to determine if there were differences in the expression of the regulatory and the catalytic subunits (p110) of Class I PI3K between the young and the aged. The results indicated that there was a statistically significant increase in the expression of p110 (Figure 1C) and p85 $\beta$ (Figure 1D) in aged compared to young adult murine splenic macrophages, stimulated with LPS for six hours. These findings were confirmed by a quantitative reverse transcriptase real time polymerase chain reaction (qRT-PCR) which showed an increase in both p110 (Figure $1 \mathrm{E}$ ) and $\mathrm{p} 85 \beta$ (Figure $1 \mathrm{~F}$ ) in aged compared to young adult macrophages. The increased magnitude of differences between young and aged in qRT-PCR versus microarray data could be due to the differences in macrophage isolation between the two studies (positive versus negative selection) and the time of stimulation (30 minutes versus 6 hours).

Therefore, we postulated that the age-associated decrease in pro-inflammatory cytokines but increase in anti-inflammatory cytokines may be due to the increased activity of PI3K.

\subsection{Age-associated increase in the activity of PI3K as shown by changes in phosphorylation of Akt}

It has been reported that the phosphorylation of Akt is an indirect way to determine the activity of PI3K (Hawkins, Anderson, Davidson, \& Stephens, 2006; Saegusa, et al., 2007; Tachado, Li, Swan, Patel, \& Koziel, 2008) since PI3K activation results in phosphorylation of Threonine-308 and then serine-473 on Akt in a temporal manner leading to an increase in its activity (Martin, Rehani, Jope, \& Michalek, 2005; Martin, et al., 2003; Pengal, et al., 2006). Therefore, levels of p-Akt were measured in young and aged splenic macrophages, as a surrogate measure of PI3K activity. Western blot analysis showed that the phosphorylation of Akt was higher in aged compared to young adult splenic macrophages stimulated with LPS. The age-associated increase in p-Akt could be shown as early as 15 minutes of stimulation with LPS and was 2.4 times more in aged than the young adult (Figure 2A). The total levels of AKT (normalized to actin) were comparable in the elderly and the young mouse macrophages.

GSK-3 is a direct downstream substrate of Akt and has been shown to be mainly involved in the differential regulation of the anti- and pro-inflammatory cytokines. GSK-3 is phosphorylated on Serine-9 resulting in its inactivation (Martin, et al., 2005; Woodgett \& Ohashi, 2005). An age-associated increase in the phosphorylation of GSK-3 would provide additional support to our hypothesis that the activity of PI3K/Akt pathway is increased in aged splenic macrophages. We employed western blot analysis to determine if the 
phosphorylation status of GSK-3 between the aged and the young correlated with the phosphorylation status of Akt. The phospho- GSK-3 $\alpha \beta$ subunits were normalized to the total GSK-3 $\beta$ subunit. GSK-3 phosphorylation was 3-fold more in the aged than the young by 15 minutes after stimulation with LPS, the TLR-4 ligand (Figures 2B). Total GSK-3 $\beta$ levels (normalized to actin) were similar between the young and the aged.

A defect in PTEN can lead to increased levels of PIP3 which in turn can result in increased PI3 Kinase activity (Butler, et al., 2002). Tachado et al. have shown that in asymptomatic HIV positive patients TNF- $\alpha$ production by TLR- 4 stimulated alveolar macrophages was suppressed due to a defect in PTEN expression leading to increased PI3K activity (Tachado, et al., 2008). Hence, we decided to quantify age-associated differences in total PTEN between the aged and the young adult splenic macrophages by Western blot. Surprisingly, there were no statistically significant differences in the total PTEN at either the basal level or upon activation with LPS (Supplementary Figure 1A). We further repeated this experiment using Pam2CSK4 as the ligand for TLR-2. Again, there were no differences in both the basal level or upon stimulation with the synthetic TLR2/6 ligand (Supplementary Figure 1B). Thus, there is an increase in the activity of PI3K, as demonstrated with increased phosphorylation of AKT and GSK-3 in aged macrophages stimulated with TLR-4 ligand and is independent of the activity of PTEN.

\subsection{Cytokine dysregulation in aged macrophages stimulated via TLR-2 and HKSP}

TLR2 is known to be required for protection against $S$. pneumoniae infection (Dessing, et al., 2009; Malley, et al., 2003). Therefore, we tested if age associated cytokine dysregulation could be shown with Pam3Csk4, a synthetic ligand for TLR2/TLR1 heterodimer. It was observed that the aged splenic macrophages stimulated with Pam-3-CSK4 produced higher levels of IL-10 compared to young adult macrophages (Figure 3A). However, there was a decrease in pro-inflammatory cytokines, such as IL-12 (Figure 3B) and IL-6 (Figure 3C).

Since, there is an increased incidence of pneumococcal infections in the elderly, we inquired if this may be partly due to a similar dysregulation in the cytokine response of macrophages to stimulation with $S$. pneumoniae. To address this question, we stimulated aged and young adult purified splenic macrophages with inactivated $S$. pneumoniae and assayed the cytokine response. The results demonstrated that there was an age-associated defect in TNF- $\alpha$ and IL-12(p40) production, in the aged compared to the young adult (Figure 3D). Thus, ageassociated cytokine dysregulation demonstrated with LPS, can also be seen in both TLR-2 and HKSP activated splenic macrophages.

\subsection{Cytokine dysregulation in aged macrophages is seen with ligands that stimulate TLR-2 receptors}

The lipoproteins or lipopeptides derived from bacteria are differentially recognized by either the TLR2/6 heterodimer or the TLR2/1 heterodimer depending on whether the cysteine residue is diacylated or triacylated. TLR2/1 ligands are typified by synthetic Pam3CSK4 while the natural ligands include mycobacterial lipoprotein and meningococcal lipoprotein. TLR2/6 recognizes the synthetic ligand Pam2CSK4 as well as mycoplasma lipoprotein, peptidoglycan (Takeuchi, et al., 2001; Wetzler, 2003). However, some studies have shown that TLR-2 can recognize some bacterial ligands such as lipoteichoic acid (LTA) independent of TLR-1 or 6 (Buwitt-Beckmann, et al., 2006) (Ozinsky, et al., 2000; Schwandner, Dziarski, Wesche, Rothe, \& Kirschning, 1999; Yoshimura, et al., 1999). Having shown that aged splenic macrophages have a defect in their ability to secrete cytokines upon stimulation with Pam3CSK4, we wondered if their responses to Pam2CSK4 and/or LTA were preserved to make them better candidates for adjuvants for the aged. Such an analysis is important since some studies find that the different TLR2 ligands use distinct 
signaling pathways and have different in vivo effects while others find the two ligands use similar signaling pathways.

We stimulated negatively purified splenic macrophages from young and aged with the TLR2/6 ligand, Pam2CSK4 for 24 hours and assayed for IL-10 (Figures 4A) and IL-12(p40) (Figures 4B). As shown in Figure 4A, the aged produced higher IL-10 than the young adult (almost undetectable) when stimulated with Pam2CSK4, but lower levels of IL-12 (p40) than the young (Figure 4B). LTA is generally recognized by a TLR2/6 heterodimer (Hoebe, et al., 2005) in macrophages similar to Pam2CSK4. Accordingly, we demonstrated that LTA was able to induce higher levels of IL-10 (Figure 4C) but lower IL-12(p40) in the splenic macrophages from aged than young mice. Since TLR4 stimulation induced increased activation of the PI3-Akt-GSK pathway in aged versus the young macrophages, we tested if stimulation with the various TLR2 ligands also resulted in greater activation of this pathway in the aged. Western blot analysis of lysates from aged and young splenic macrophages stimulated with Pam2CSK4 showed that there was a 2.7 and 3.5 fold increase in P-AKT in the aged versus the young adult macrophages stimulated for 15 and 30 minutes respectively (Supplementary Figure 2A). We also investigated the effect of age-associated increase in the phosphorylation of AKT on phosphorylation of its downstream target, GSK-3, in the context of TLR2/6 (Pam2CSK4). The Western blot analysis showed that the levels of P-GSK-3 were 3.3 and 10 fold more in the aged than in the young (Supplementary Figure 2B) at zero and 15 minutes of stimulation respectively. Similarly stimulation of macrophages with LTA also demonstrated increased levels of P-GSK-3 in the aged compared to the young (Supplemental Figure 2C). Thus PI3K pathway activity is increased in the aged splenic macrophages upon stimulation with both TLR4 and TLR2 ligands.

\subsection{PI3K inhibitors partially rescue the age-associated defect in TLR-4 induced cytokine production}

We wondered if the increase in the activity of PI3K has a role in the decreased production of the pro-inflammatory cytokines and increased IL-10 secretion in the aged (Pengal, et al., 2006; Saegusa, et al., 2007). Hence, splenic macrophages from aged and young adults were treated with either LY294002 or wortmannin, two well characterized PI3K inhibitors and then stimulated with LPS, the TLR-4 ligand to initiate cytokine production. At 2 and $5 \mu \mathrm{M}$ of LY294002 there was a reduction in the levels of IL-10 in both aged and young macrophages stimulated with LPS (Figure 5A). At $50 \mathrm{nM}$, wortmannin had a more profound inhibitory effect on IL-10 production by the aged than the young macrophages (Figure 5A). As predicted, treatment of splenic macrophages with LY294002 resulted in the enhancement of IL-12(p40) in aged splenic macrophages, but not in the young adult (Figure 5B). The lack of enhancement in the young was surprising but was reproducible. However, when wortmannin was used as an inhibitor, there was a small but significant increase in IL-12(p40) in both age groups at $5 \mathrm{nM}$ and $50 \mathrm{nM}$ (Figure 5B) but the magnitude of increase in IL-12 with wortmannin was smaller in the young than in the aged. Thus, cytokine dysregulation in the aged appears to be linked to a defect in the PI3K-Akt pathway and this can be partially rescued by inhibiting PI3K with either LY294002 or wortmannin.

To be certain that the PI3K specific inhibitors were indeed blocking the PI3K/Akt pathway, Akt activation was evaluated by quantifying p-Akt levels in young macrophages treated with wortmannin or LY294002. LPS stimulation increased p-Akt levels compared to unstimulated cells. Inhibition of PI3K with wortmannin in the presence of LPS resulted in 1.6 fold reduction in the level of P-Akt compared to cells activated with LPS in the absence of the inhibitor at the 30 minute time point (Figure 5C; Lanes 3 and 4). Similarly with LY294002, another PI3K inhibitor, there was a reduction in LPS induced activation of Akt, by 3.7 fold at the 30 minute time point (Figure 5C; Lanes 3 and 5). To demonstrate that phosphorylation of GSK-3 in splenic macrophages is indeed dependent on the PI3K/Akt 
pathway, we determined if inhibition of PI3K with either LY294002 or wortmannin will affect p-GSK-3 levels (Martin, et al., 2005). As shown in Figure 5D stimulation of macrophages with LPS resulted in an increase in GSK-3 phosphorylation at 15 and 30 minutes of stimulation. Treatment with wortmannin or by LY294002 decreased GSK-3 phosphorylation by 2.1 and 2.8 fold compared to untreated group after 30 minutes of LPS stimulation. Thus, activation of PI3K with TLR-4 ligand resulted in an increase in phosphorylation of Akt and GSK-3, which was reduced significantly by inhibition of PI3K.

\subsection{The ability of LY294002 or wortmannin to modulate the age-associated defect in PI3K signaling on cytokine production can also be shown with TLR-2 ligands}

We decided to investigate the possibility that decrease in secretion of pro-inflammatory cytokines in response to TLR2 ligands, might also be rescued by PI3K inhibitors because TLR2 signaling uses the same MyD88 adaptor as the TLR4 receptors (Dessing, et al., 2009; Hashimoto, et al., 2006; Snapper, et al., 1995). Purified splenic macrophages from aged and young adult were pre-treated with LY294002 or wortmannin and then stimulated with Pam-2-CSK4 $(1 \mu \mathrm{g} / \mathrm{ml})$ or LTA. Treatment with the LY294002 reduced IL-10 secretion in the presence of both Pam2CSK4 and LTA (Figure 6A) and increased IL-12(p40) secretion when either Pam2CSK4 (Figure 6B) or LTA (Figure 6C) was used as the TLR-2 agonist in the aged. Interestingly, the PI3K inhibitor induced very little or no increase in cytokine secretion by young macrophages. Similar results were obtained when Pam-3-CSK-4 was used to stimulate macrophages in the presence of the PI3K inhibitor. Thus IL-10 was reduced in both aged and young splenic macrophages when PI3K was inhibited, (Supplementary Figure 3A). Moreover, treatment with LY294002 resulted in an increase in IL-6 (Supplementary Figure 3B) and IL-1 12(p40) (Supplementary Figure 3C) in aged splenic macrophages, an effect that was not seen in the young adult (Supplementary Figures $3 \mathrm{~B}$ and $3 \mathrm{C})$.

Thus, PI3K inhibition results in reduced secretion of IL-10 but increased pro-inflammatory cytokines in the aged when any of the TLR-2 ligands are used to stimulate the macrophages. Moreover, PI3K inhibition regulated cytokine secretion more in the aged than in the young adult.

\subsection{PI3K inhibition enhanced the HKSP mediated induction of pro-inflammatory cytokines in aged splenic macrophages}

As shown in Figure 3D, HKSP induced pro-inflammatory cytokines are decreased in the aged. HKSP has been shown to interact with splenic macrophages via TLR-2, 4 and 9 and induce the secretion of both pro- and anti-inflammatory cytokines (Dessing, Florquin, Paton, \& van der Poll, 2008; Dessing, et al., 2009; Lee, et al., 2007). Therefore, we tested if the impairment in HKSP-induced production of pro-inflammatory cytokines is also dependent on heightened PI3K activity in the aged, using LY294002 and wortmannin. Stimulating aged splenic macrophages with HKSP in the presence of LY294002 resulted in enhancement of HKSP induced secretion of IL-6 (Figure 7A). Similarly, treatment with wortmannin also enhanced secretion of both IL-6 (Figure 6B) and IL-12(p40) (Figure 7D) by HKSP stimulated aged macrophages. IL-12(p70) was measured (Figure 7C) since the $\mathrm{P} 40$ subunit is also shared with IL-23. HKSP alone did not induce much p70 but treatment with wortmannin dramatically enhanced p70 levels. Similarly, induction of IL-12 (p70) by Pam-3-CSK4 was also enhanced by PI3K inhibition (data not shown).

\subsection{Age-associated cytokine dysregulation involving TLR-2 and HKSP is due to a defect in the Akt-GSK-3 signaling axis}

Here we asked if the ability of the PI3K inhibitors to enhance TLR2 induced secretion of pro-inflammatory cytokine secretion is due to a reduction in the activation of $\mathrm{p}$-Akt and $\mathrm{p}$ - 
GSK3, two downstream targets of the PI3K pathway. Inhibition of PI3K with $20 \mu \mathrm{M}$ of LY294002 in the presence of P3C $(1 \mu \mathrm{g} / \mathrm{ml})$ resulted in $40 \%$ reduction in P-Akt compared to P3C activation without the inhibitor (Figure 8A: lanes 2 and 3) when the densitometry of PAkt was compared to total Akt. Since the loading was unequal between lanes 2 and lane 3, we also compared the band intensity of p-Akt to that of $\beta$-actin band which showed a $76 \%$ reduction in p-Akt in LY pretreated cells compared to $\mathrm{P} 3 \mathrm{C}$ stimulation without the inhibitor (Figure 8A: lanes 2 and 3). Treatment of Pam3CSK4 stimulated macrophages with wortmannin at 30 minutes resulted in a 28\% reduction in P-GSK-3 $\alpha \beta$ (Figure 8B: lanes 3 and 4). When LY294002 was used, TLR-2 stimulated macrophages at 30 minutes showed a 56\% reduction in P-GSK-3 $\alpha \beta$ levels (Figure 8B: Lanes 3 and 5). Given the consistency in the reduction of P-GSK-3 upon stimulation of purified splenic macrophages with both TLR-2 and TLR-4 ligands in the presence of PI3K inhibitors, it was of interest to evaluate the effect of stimulating aged splenic macrophages with HKSP in the presence of LY294002. HKSP was effective in activating the PI3K-Akt signaling pathway, as indicated by an increase in the phosphorylation of GSK-3 (Figure 8C: Lanes 1 and 2). Inhibition of PI3K with LY294002 resulted in a 52\% reduction in the levels of P-GSK-3 (Figure 8C: Lanes 2 and 3). Thus, activation of PI3K with TLR-2 or HKSP resulted in an increase in phosphorylation of Akt and GSK-3, which was reduced significantly by inhibition of PI3K.

\subsection{Effect of PI3K inhibition on cytokine secretion by splenic macrophages stimulated with interleukin-1 $\beta$ (IL-1 $\beta$ ) is similar to TLR induction}

Thus far we have shown an age associated cytokine dysregulation using ligands for TLR1/2, TLR2/6 and TLR4 receptors, all of which use the MyD88/Mal heterodimer for signal transduction. Hence one cannot distinguish if signal transduction via MyD88 or Mal is different in the aged compared to the young. Hence, we tested the effect of aging on IL-1 $\beta$ induced responses of macrophages, since IL-1 $\beta$ has been shown to use MyD88 but not Mal for signal transduction (Rijneveld, et al., 2003). Moreover IL-1 $\beta$ has been shown to be critical for the clearance of $S$. Pneumoniae via both macrophage activation and antipolysaccharide antibody production by B-cells (R. L. Chelvarajan, et al., 1998; Kafka, et al., 2008). Very little is known about the role of the PI3K-AKT-GSK-3 signaling axis in regulating IL-1 $\beta$-mediated induction of IL-10 and the pro-inflammatory cytokines in the context of aged splenic macrophages. Inhibition of PI3K pathway with LY294002 resulted in a suppression of IL-1 induced IL-10 secretion (Figuire 9A) but an enhancement of IL-6 secretion (Figure 9B) similar to our results with TLR2 and TLR4 ligands. This suggests that major target of PI3kinase-Akt-GSK-3 axis is in regulation of the MyD88 pathway in macrophages, which is consistent with the recent findings that the $\mathrm{p} 85$ subunit of PI3K directly interacts with MyD88 (Laird et al 2009).

\subsection{Discussion}

Immune responses to infection, in particular to encapsulated bacteria, are decreased in the aged. Previously, we have shown that antibody responses to polysaccharide antigens, one of the protective antigens for infections with pneumococcal bacteria, are decreased in the aged, in part due to defects in macrophage function (R. L. Chelvarajan, et al., 2005). Using TLR-4 activation as a model system we have shown that the splenic macrophages from the aged exhibit a cytokine dysregulation phenotype with a decrease in pro-inflammatory cytokines required for B cell activation. Using gene expression studies we also showed that this is due to a decrease in the activation of the MyD88 signaling pathway leading to a decrease in ERK activation but an aberrant increase in p38 MAP kinase activation (R. L. Chelvarajan, et al., 2006). Since the immune responses to Gram positive bacteria such as $S$. pneumoniae are also dependent on TLR2 activation (Dessing, et al., 2009; Seo, et al., 2008) and since TLR2 ligands also utilize the MyD88 signaling pathway, we hypothesized that splenic 
macrophages from the aged would exhibit a cytokine dysregulation phenotype with synthetic TLR2 ligands or intact bacteria similar to that seen with TLR4 activation. Indeed, studies presented here demonstrated that activation with HKSP or any of the TLR-2 ligands, Pam3-CSK4, Pam-2-CSK4 or LTA induces lower levels of pro-inflammatory cytokines such as IL-12 but higher levels of anti-inflammatory cytokines such as IL-10 in splenic macrophages from the aged compared to cells from the young. Together with our previous studies, these results demonstrate that immunosenescence affects responses of splenic macrophages to both TLR2 and TLR4 ligands.

To understand the signaling mechanism governing this age-associated cytokine dysregulation, we evaluated the activity of PI3K, a well established switch-factor for proand anti- inflammatory cytokines (Fukao \& Koyasu, 2003; Polumuri, et al., 2007; Saegusa, et al., 2007). An analysis of our previous data on gene expression in highly purified splenic macrophages (R. L. Chelvarajan, et al., 2006) revealed that there was an age-associated increase in expression of genes encoding both the catalytic (p1108) and the regulatory (p85 $\beta$ ) subunits of the Class IA PI3 kinase, which was further validated by qRT real time PCR. There was an increase in functionally active PI3-kinase in the aged as shown by an increase in the phosphorylation of its downstream target, Akt, in splenic macrophages stimulated by ligands for TLR-2 and TLR-4. Moreover, phosphorylation of GSK-3, an immediate downstream target of Akt (Hazeki, et al., 2007; Martin, et al., 2005), also was increased in TLR-2 and TLR-4 stimulated splenic macrophages from the aged compared to the young. Thus, the PI3K-Akt-GSK-3 pathway that is known to negatively regulate proinflammatory cytokine production was upregulated in macrophages from the aged. The increase in activity of this pathway was seen in macrophages from the aged stimulated with TLR2 or TLR4 ligands as well as HKSP.

We next asked if inhibitors of PI3K could restore pro-inflammatory cytokine production and decrease IL-10 production by TLR-2 or 4 stimulated macrophages from the aged. Accordingly, we showed that PI3K inhibitors enhanced IL-12(p40) production and decreased IL-10 secretion by aged mouse splenic macrophages stimulated with either TLR-2 or TLR4 ligands. However, under these conditions PI3K inhibitors did not have much effect on cytokine secretion by young adult splenic macrophages, stimulated with TLR-2 or 4 ligands. Despite previous studies demonstrating specificity of wortmannin and LY294002 to Class I isoform, more recent studies found that one of the Class II isoforms is also inhibited by these reagents, albeit at 50-100 fold higher concentration (Hawkins, et al., 2006;

Misawa, et al., 1998; Stack \& Emr, 1994; Stephens, et al., 1994; Virbasius, Guilherme, \& Czech, 1996). Currently we are devising an RNAi approach to establish the relative importance of PI3K isoforms in age-related cytokine dysregulation.

Our finding that in vitro stimulation of purified splenic macrophages produced higher IL-10 but lower pro-inflammatory cytokines in the aged than in young is consistent with other published work (Boehmer, et al., 2004; R. L. Chelvarajan, et al., 2005; Panda, et al., 2010; Renshaw, et al., 2002). In contrast, there are several reports that IL-6 levels are increased in the elderly and contribute to basal inflammation (Bruunsgaard \& Pedersen, 2003;

Franceschi, et al., 2000). This apparent inconsistency between the in vitro and in vivo cytokine profile has been attributed to the criteria used to select elderly subjects (Ahluwalia, et al., 2001). It has been shown that the frail elderly already have predisposing underlying diseases that impact on basal inflammation, whereas, in the healthy elderly, the inflammation is controlled by the increase in the levels of IL-10 (Ahluwalia, et al., 2001; Larbi, et al., 2008). Thus, Njemini et al (2007) found that IL-6 levels in healthy elderly were less than in young adult but that the levels of IL-6 are more in elderly than young when there is evidence of infection. Additionally, work from Kovacs laboratory (Gomez, et al., 2010) has further confirmed the in vitro defect in production of pro-inflammatory cytokines by 
LPS activated macrophages from the aged. Interestingly, aged IL-6 knockout mice made more TNF- $\alpha$, IL-12 and IL- 6 than young IL- 6 knockout mice suggesting a role for systemic IL-6 in the cytokine defect of aged mice. However, IL-6 regulation is complex since young IL-6 knockout mice made less IL-1, IL-12 and TNF- $\alpha$ than young wild type mice (Gomez, et al., 2010).

Working with monocyte derived dendritic cells (MDDC) from the elderly; Agrawal et al (Agrawal, et al., 2007) showed that the age-associated increase in the pro-inflammatory cytokines is due to a decrease in PI3K activity and increased activity of P38 MAP Kinase. These discrepant results could be due to the use of splenic macrophages in our study; while peripheral blood monocyte derived dendritic cells were used by Agrawal et al and/or due to differences between the murine and human systems. In contrast to this study with DCs and in agreement with our studies Panda et al reported that elderly human myeloid and plasmacytoid DC from peripheral blood mononuclear cells exhibited a defect in the production of pro-inflammatory cytokines (Panda, et al., 2010).

Using Zymosan, a yeast derived TLR-2 ligand, to stimulate purified splenic macrophages, Boehmer et al (Boehmer, et al., 2005) also found that IL-6 was decreased in the aged. However, it was shown that there was no difference in the cytokine levels between the aged and the young adult in terms of IL-10. This apparent contradiction from our finding that IL-10 was higher in the aged compared to the young could possibly be explained first by putative differences in the signaling mechanism between Zymosan and the other TLR2 ligands used here. Zymosan has been shown to interact with dectin-1 to stimulate production of pro-inflammatory cytokines (Dennehy, et al., 2008; Dillon, et al., 2006; Du, et al., 2006). Pam-3-CSK4 is not known to signal via dectin-1 to induce cytokine production (Gantner, Simmons, Canavera, Akira, \& Underhill, 2003). A second plausible reason for this apparent contradiction could be due to the method by which the macrophages were purified. We used negative selection to isolate the splenic macrophages and thus kept them unperturbed. Boehmer et al used adherence to isolate macrophages, which is known to activate macrophages (De Sole, et al., 1992; Kelley, Rozek, Suenram, \& Schwartz, 1987).

Although, we observed the expected negative effects of PI3K on pro-inflammatory cytokines in the aged, we were surprised to note that the effects of PI3K inhibitors on cytokine secretion by young splenic macrophages were very modest and were seen only in certain groups. Interestingly most of the studies that were performed with young macrophages to investigate the role of PI3K and cytokine regulation used human monocytes, murine peritoneal macrophages, alveolar macrophages and macrophage-derived cell lines like THP-1 and RAW 264.7 cells but not splenic macrophages (Luyendyk, et al., 2008; Martin, et al., 2003; Pengal, et al., 2006; Saegusa, et al., 2007; Tachado, et al., 2008; Weichhart, et al., 2008). It is possible that the PI3K pathway may not have major negative effects on TLR signaling in young adult splenic macrophages, due to the low expression of the PI3K enzyme. More profound effects may have been seen in the aged due to increased expression of PI3K subunits.

The association between the increased activity of PI3K and a defect in PTEN expression is well established (Marone, et al., 2008). PTEN has been shown to promote pro-inflammatory activity of macrophages (Cao, et al., 2004). MDDCs from elderly were shown to have increased PTEN levels (Agrawal, et al., 2007). However, we did not note any difference in the level of PTEN between aged and young adult spleen macrophages. This apparent contradiction regarding age associated changes in PTEN levels may also be due to differences between macrophages and DCs and/or due to differences between human and mouse. 
We propose a model (Supplementary Figure 4) in which there is a heightened activity of PI3K in the aged (Supplementary Figure 4A) resulting in increased phosphorylation of Akt. The increased activity of Akt results in a further phosphorylation of GSK-3 and reduction in its activity. We propose that the reduction in the activity of GSK-3 affects transcription factors like CREB, AP-1 and p65NFkB resulting in increased IL-10 but a decrease in the pro-inflammatory cytokines such as IL-12, IL- 6 and TNF- $\alpha$. Inhibiting PI3K reverses this phenotype to that of a young adult (Supplementary Figure 4B) with increases in the proinflammatory cytokines over IL-10. We are currently investigating the effect of modulating PI3K on transcription factors CREB, AP-1 and p65NFkB. Here we have included TLR2/ TLR6 heterodimers and IL-1R since we find similar results with Pam2CSK4 (TLR2/6 ligand) and IL-1.

The biological significance of our findings is that these inhibitors could be used to reverse the effect of aging on macrophage function. We have shown that macrophages and macrophage-mediated cytokine defects in the aged were critical factors responsible for the impaired anti-capsular antibody response in the aged (Bondada, et al., 2000; R. L.

Chelvarajan, et al., 2005). We have also shown that the humoral response of the aged to polysaccharide vaccine or TNP-Ficoll and TNP-LPS, representative thymic independent antigens, could be enhanced if aged B-lymphocytes are provided with either young macrophages or macrophage-derived cytokines like IL-6 and IL-1 $\beta$ (R. L. Chelvarajan, et al., 2005; Garg, et al., 1996). Others have shown that antibody response to infection with $S$. pneumoniae could also be enhanced in the presence of IL-12 (Arulanandam, et al., 2001; Metzger, et al., 1996; Sun, Salmon, Lotz, \& Metzger, 2007). We propose that PI3K inhibition could be used to enhance the macrophage-derived cytokines that are known to provide the signal 2 needed to activate B cells and mount an effective antibody response to S. pneumoniae and/or pneumococcal polysaccharide vaccines in the elderly. In conclusion, we have made a novel observation that the age-associated increase in PI3K-Akt activity is a signaling defect that contributes to the cytokine dysregulation observed in the aged and that PI3K inhibitors may be useful as unique adjuvants to enhance immune responses in the aged.

\section{RESEARCH HIGHLIGHTS}

$>\quad$ There is an age-associated heightened activity of the Class IA PI3K at the mRNA level in LPS stimulated splenic macrophages.

$>\quad$ The heightened activity of PI3K in the aged splenic macrophages can be validated indirectly by the increased phosphorylation of AKT and GSK-3 upon TLR-4 stimulation.

$>\quad$ Aged splenic macrophages exhibit cytokine dysregulation upon stimulation with ligands for TLR-2 and TLR-4 receptors.

$>\quad$ The age-related increase in activity of PI3K suppresses the pro-inflammatory cytokines but enhances IL-10 as shown by the ability of the PI3K pharmacological inhibitors, LY294002 and wortmannin to partially rescue this cytokine dysregulation in the presence of TLR-4 agonist.

$>\quad$ The aging phenomenon leading to increased PI3K activity can be recapitulated via western blots for P-Akt and P-GSK-3 in the context of stimulation with TLR2 /TLR-1 or TLR-2/TLR-6 heterodimers and HKSP.

This finding is the first that directly links age-associated heightened activity of PI3K as a mechanism for cytokine dysregulation in macrophages in the context of TLR-2 and TLR-4 as well as HKSP. 


\section{Supplementary Material}

Refer to Web version on PubMed Central for supplementary material.

\section{ABBREVIATIONS}

\begin{tabular}{|c|c|}
\hline CBP & CREB-binding protein \\
\hline CREB & cAMP-response element-binding protein \\
\hline DCs & dendritic cells \\
\hline ERK & extracellular-signal-regulated kinase \\
\hline ELISA & enzyme-linked immunosorbent assay \\
\hline FcyR & Fc $\gamma$ receptor \\
\hline FITC & Fluorescein isothiocyanate (FITC) \\
\hline GSK-3 & Glycogen synthase kinase-3 \\
\hline HKSP & heat killed Streptococcus pneumoniae \\
\hline IL-1及 & Interleukin -1 beta \\
\hline LPS & Lipopolysaccharide \\
\hline $\mathbf{L Y}$ & LY294002 \\
\hline MAPK & Mitogen activated protein kinase \\
\hline MDDC & monocyte derived dendritic cells \\
\hline MyD88 & Myeloid differentiation primary response genes 88 \\
\hline Pam-3-CSK4 & N-Palmitoyl-S-[2,3-bis(palmitoyloxy)-(2RS)-propyl]-[R]-C-S-Lys4 \\
\hline PI3K & phosphatidyl inositol 3-kinase (PI3K) \\
\hline S. pneumoniae & Streptococcus pneumoniae \\
\hline TNP-Ficoll & trinitrophenol conjugated to Ficoll \\
\hline TNP-LPS & trinitrophenol conjugated to LPS \\
\hline PTEN & phosphatase and tensin homolog \\
\hline qRT RT-PCR & quantitative reverse transcriptase polymerase chain reaction \\
\hline TLR & Toll like receptor \\
\hline
\end{tabular}

\section{Acknowledgments}

This study was supported by NIH grants to SB. We thank Dr. Kaplan for his critical comments on the manuscript, Dr. Maria Bruno for help with the RT-PCR.

\section{REFERENCES}

Agrawal A, Agrawal S, Cao JN, Su H, Osann K, Gupta S. Altered innate immune functioning of dendritic cells in elderly humans: a role of phosphoinositide 3-kinase-signaling pathway. J Immunol. 2007; 178(11):6912-6922. [PubMed: 17513740]

Ahluwalia N, Mastro AM, Ball R, Miles MP, Rajendra R, Handte G. Cytokine production by stimulated mononuclear cells did not change with aging in apparently healthy, well-nourished women. Mechanisms of Ageing and Development. 2001; 122(12):1269-1279. [PubMed: 11438118] 
Arulanandam BP, Lynch JM, Briles DE, Hollingshead S, Metzger DW. Intranasal vaccination with pneumococcal surface protein A and interleukin-12 augments antibody-mediated opsonization and protective immunity against Streptococcus pneumoniae infection. Infect Immun. 2001; 69(11): 6718-6724. [PubMed: 11598043]

Boehmer ED, Goral J, Faunce DE, Kovacs EJ. Age-dependent decrease in Toll-like receptor 4mediated proinflammatory cytokine production and mitogen-activated protein kinase expression. $\mathrm{J}$ Leukoc Biol. 2004; 75(2):342-349. [PubMed: 14634059]

Boehmer ED, Meehan MJ, Cutro BT, Kovacs EJ. Aging negatively skews macrophage TLR2- and TLR4-mediated pro-inflammatory responses without affecting the IL-2-stimulated pathway. Mech Ageing Dev. 2005; 126(12):1305-1313. [PubMed: 16154177]

Bondada S, Wu H, Robertson DA, Chelvarajan RL. Accessory cell defect in unresponsiveness of neonates and aged to polysaccharide vaccines. Vaccine. 2000; 19(4-5):557-565. [PubMed: 11027821]

Bruunsgaard H, Pedersen BK. Age-related inflammatory cytokines and disease. Immunol Allergy Clin North Am. 2003; 23(1):15-39. [PubMed: 12645876]

Butler M, McKay RA, Popoff IJ, Gaarde WA, Witchell D, Murray SF, et al. Specific inhibition of PTEN expression reverses hyperglycemia in diabetic mice. Diabetes. 2002; 51(4):1028-1034. [PubMed: 11916922]

Buwitt-Beckmann U, Heine H, Wiesmuller KH, Jung G, Brock R, Akira S, et al. TLR1- and TLR6independent recognition of bacterial lipopeptides. J Biol Chem. 2006; 281(14):9049-9057. [PubMed: 16455646]

Cao X, Wei G, Fang H, Guo J, Weinstein M, Marsh CB, et al. The inositol 3-phosphatase PTEN negatively regulates Fc gamma receptor signaling, but supports Toll-like receptor 4 signaling in murine peritoneal macrophages. J Immunol. 2004; 172(8):4851-4857. [PubMed: 15067063]

Cen L, Hsieh FC, Lin HJ, Chen CS, Qualman SJ, Lin J, et al. PDK-1/AKT pathway as a novel therapeutic target in rhabdomyosarcoma cells using OSU-03012 compound. Br J Cancer. 2007; 97(6):785-791. [PubMed: 17848913]

Chelvarajan L, Popa D, Liu Y, Getchell TV, Stromberg AJ, Bondada S. Molecular mechanisms underlying anti-inflammatory phenotype of neonatal splenic macrophages. J Leukoc Biol. 2007; 82(2):403-416. [PubMed: 17495050]

Chelvarajan RL, Collins SM, Van Willigen JM, Bondada S. The unresponsiveness of aged mice to polysaccharide antigens is a result of a defect in macrophage function. J Leukoc Biol. 2005; 77(4): 503-512. [PubMed: 15629885]

Chelvarajan RL, Gilbert NL, Bondada S. Neonatal murine B lymphocytes respond to polysaccharide antigens in the presence of IL-1 and IL-6. J Immunol. 1998; 161(7):3315-3324. [PubMed: 9759847]

Chelvarajan RL, Liu Y, Popa D, Getchell ML, Getchell TV, Stromberg AJ, et al. Molecular basis of age-associated cytokine dysregulation in LPS-stimulated macrophages. J Leukoc Biol. 2006; 79(6):1314-1327. [PubMed: 16603589]

De Sole P, Frigieri L, Fresu R, Di Mario G, Corvaglia AG, Petrosino A, et al. Chemiluminescence of bronchoalveolar macrophages: effect of adherence to plastic cuvette. Arch Immunol Ther Exp (Warsz). 1992; 40(1):55-58. [PubMed: 1485828]

Dennehy KM, Ferwerda G, Faro-Trindade I, Pyz E, Willment JA, Taylor PR, et al. Syk kinase is required for collaborative cytokine production induced through Dectin-1 and Toll-like receptors. Eur J Immunol. 2008; 38(2):500-506. [PubMed: 18200499]

Dessing MC, Florquin S, Paton JC, van der Poll T. Toll-like receptor 2 contributes to antibacterial defence against pneumolysin-deficient pneumococci. Cell Microbiol. 2008; 10(1):237-246. [PubMed: 17711480]

Dessing MC, Hirst RA, de Vos AF, van der Poll T. Role of Toll-like receptors 2 and 4 in pulmonary inflammation and injury induced by pneumolysin in mice. PLoS One. 2009; 4(11):e7993. [PubMed: 19956717]

Dillon S, Agrawal S, Banerjee K, Letterio J, Denning TL, Oswald-Richter K, et al. Yeast zymosan, a stimulus for TLR2 and dectin-1, induces regulatory antigen-presenting cells and immunological tolerance. J Clin Invest. 2006; 116(4):916-928. [PubMed: 16543948] 
Du Z, Kelly E, Mecklenbrauker I, Agle L, Herrero C, Paik P, et al. Selective regulation of IL-10 signaling and function by zymosan. J Immunol. 2006; 176(8):4785-4792. [PubMed: 16585572]

Farhat K, Riekenberg S, Heine H, Debarry J, Lang R, Mages J, et al. Heterodimerization of TLR2 with TLR1 or TLR6 expands the ligand spectrum but does not lead to differential signaling. J Leukoc Biol. 2008; 83(3):692-701. [PubMed: 18056480]

Franceschi C, Bonafe M, Valensin S, Olivieri F, De Luca M, Ottaviani E, et al. Inflammaging. An evolutionary perspective on immunosenescence. Ann N Y Acad Sci. 2000; 908:244-254. [PubMed: 10911963]

Fukao T, Koyasu S. PI3K and negative regulation of TLR signaling. Trends in Immunology. 2003; 24(7):358-363. [PubMed: 12860525]

Gantner BN, Simmons RM, Canavera SJ, Akira S, Underhill DM. Collaborative induction of inflammatory responses by dectin-1 and Toll-like receptor 2. J Exp Med. 2003; 197(9):1107-1117. [PubMed: 12719479]

Garg M, Luo W, Kaplan AM, Bondada S. Cellular basis of decreased immune responses to pneumococcal vaccines in aged mice. Infect Immun. 1996; 64(11):4456-4462. [PubMed: 8890192]

Gomez CR, Karavitis J, Palmer JL, Faunce DE, Ramirez L, Nomellini V, et al. Interleukin-6 contributes to age-related alteration of cytokine production by macrophages. Mediators Inflamm. 2010; 2010:475139. [PubMed: 20671912]

Han SH, Kim JH, Martin M, Michalek SM, Nahm MH. Pneumococcal lipoteichoic acid (LTA) is not as potent as staphylococcal LTA in stimulating Toll-like receptor 2. Infect Immun. 2003; 71(10): 5541-5548. [PubMed: 14500472]

Hashimoto M, Tawaratsumida K, Kariya H, Kiyohara A, Suda Y, Krikae F, et al. Not lipoteichoic acid but lipoproteins appear to be the dominant immunobiologically active compounds in Staphylococcus aureus. J Immunol. 2006; 177(5):3162-3169. [PubMed: 16920954]

Hawkins PT, Anderson KE, Davidson K, Stephens LR. Signalling through Class I PI3Ks in mammalian cells. Biochem Soc Trans. 2006; 34(Pt 5):647-662. [PubMed: 17052169]

Hazeki K, Nigorikawa K, Hazeki O. Role of phosphoinositide 3-kinase in innate immunity. Biol Pharm Bull. 2007; 30(9):1617-1623. [PubMed: 17827709]

Hoebe K, Georgel P, Rutschmann S, Du X, Mudd S, Crozat K, et al. CD36 is a sensor of diacylglycerides. Nature. 2005; 433(7025):523-527. [PubMed: 15690042]

Jackson LA, Janoff EN. Pneumococcal vaccination of elderly adults: new paradigms for protection. Clin Infect Dis. 2008; 47(10):1328-1338. [PubMed: 18844484]

Kafka D, Ling E, Feldman G, Benharroch D, Voronov E, Givon-Lavi N, et al. Contribution of IL-1 to resistance to Streptococcus pneumoniae infection. Int Immunol. 2008; 20(9):1139-1146. [PubMed: 18596024]

Katso R, Okkenhaug K, Ahmadi K, White S, Timms J, Waterfield MD. Cellular function of phosphoinositide 3-kinases: implications for development, homeostasis, and cancer. Annu Rev Cell Dev Biol. 2001; 17:615-675. [PubMed: 11687500]

Kelley JL, Rozek MM, Suenram CA, Schwartz CJ. Activation of human blood monocytes by adherence to tissue culture plastic surfaces. Exp Mol Pathol. 1987; 46(3):266-278. [PubMed: 3036568]

Kerr AR, Irvine JJ, Search JJ, Gingles NA, Kadioglu A, Andrew PW, et al. Role of inflammatory mediators in resistance and susceptibility to pneumococcal infection. Infect Immun. 2002; 70(3): 1547-1557. [PubMed: 11854243]

Khan AQ, Shen Y, Wu ZQ, Wynn TA, Snapper CM. Endogenous pro- and anti-inflammatory cytokines differentially regulate an in vivo humoral response to Streptococcus pneumoniae. Infect Immun. 2002; 70(2):749-761. [PubMed: 11796608]

Koyasu S. The role of PI3K in immune cells. Nat Immunol. 2003; 4(4):313-319. [PubMed: 12660731]

Laird MH, Rhee SH, Perkins DJ, Medvedev AE, Piao W, Fenton MJ, et al. TLR4/MyD88/PI3K interactions regulate TLR4 signaling. J Leukoc Biol. 2009; 85(6):966-977. [PubMed: 19289601]

Larbi A, Franceschi C, Mazzatti D, Solana R, Wikby A, Pawelec G. Aging of the immune system as a prognostic factor for human longevity. Physiology (Bethesda). 2008; 23:64-74. [PubMed: 18400689] 
Lee KS, Scanga CA, Bachelder EM, Chen Q, Snapper CM. TLR2 synergizes with both TLR4 and TLR9 for induction of the MyD88-dependent splenic cytokine and chemokine response to Streptococcus pneumoniae. Cell Immunol. 2007; 245(2):103-110. [PubMed: 17521621]

Luyendyk JP, Schabbauer GA, Tencati M, Holscher T, Pawlinski R, Mackman N. Genetic analysis of the role of the PI3K-Akt pathway in lipopolysaccharide-induced cytokine and tissue factor gene expression in monocytes/macrophages. J Immunol. 2008; 180(6):4218-4226. [PubMed: 18322234]

Lynch JP 3rd, Zhanel GG. Streptococcus pneumoniae: epidemiology, risk factors, and strategies for prevention. Semin Respir Crit Care Med. 2009; 30(2):189-209. [PubMed: 19296419]

Lynch JP 3rd, Zhanel GG. Streptococcus pneumoniae: epidemiology and risk factors, evolution of antimicrobial resistance, and impact of vaccines. Curr Opin Pulm Med. 2010; 16(3):217-225. [PubMed: 20375783]

Makela SM, Strengell M, Pietila TE, Osterlund P, Julkunen I. Multiple signaling pathways contribute to synergistic TLR ligand-dependent cytokine gene expression in human monocyte-derived macrophages and dendritic cells. J Leukoc Biol. 2009; 85(4):664-672. [PubMed: 19164128]

Malley R, Henneke P, Morse SC, Cieslewicz MJ, Lipsitch M, Thompson CM, et al. Recognition of pneumolysin by Toll-like receptor 4 confers resistance to pneumococcal infection. Proc Natl Acad Sci U S A. 2003; 100(4):1966-1971. [PubMed: 12569171]

Marone R, Cmiljanovic V, Giese B, Wymann MP. Targeting phosphoinositide 3-kinase: moving towards therapy. Biochim Biophys Acta. 2008; 1784(1):159-185. [PubMed: 17997386]

Martin M, Rehani K, Jope RS, Michalek SM. Toll-like receptor-mediated cytokine production is differentially regulated by glycogen synthase kinase 3. Nat Immunol. 2005; 6(8):777-784. [PubMed: 16007092]

Martin M, Schifferle RE, Cuesta N, Vogel SN, Katz J, Michalek SM. Role of the phosphatidylinositol 3 kinase-Akt pathway in the regulation of IL-10 and IL-12 by Porphyromonas gingivalis lipopolysaccharide. J Immunol. 2003; 171(2):717-725. [PubMed: 12847238]

Metzger DW, Buchanan JM, Collins JT, Lester TL, Murray KS, Van Cleave VH, et al. Enhancement of humoral immunity by interleukin-12. Ann N Y Acad Sci. 1996; 795,:100-115. [PubMed: 8958921]

Misawa H, Ohtsubo M, Copeland NG, Gilbert DJ, Jenkins NA, Yoshimura A. Cloning and characterization of a novel class II phosphoinositide 3-kinase containing C2 domain. Biochem Biophys Res Commun. 1998; 244(2):531-539. [PubMed: 9514948]

Njemini R, Bautmans I, Lambert M, Demanet C, Mets T. Heat shock proteins and chemokine/cytokine secretion profile in ageing and inflammation. Mech Ageing Dev. 2007; 128(7-8):450-454. [PubMed: 17644159]

Ozinsky A, Underhill DM, Fontenot JD, Hajjar AM, Smith KD, Wilson CB, et al. The repertoire for pattern recognition of pathogens by the innate immune system is defined by cooperation between toll-like receptors. Proc Natl Acad Sci U S A. 2000; 97(25):13766-13771. [PubMed: 11095740]

Panda A, Qian F, Mohanty S, van Duin D, Newman FK, Zhang L, et al. Age-associated decrease in TLR function in primary human dendritic cells predicts influenza vaccine response. J Immunol. 2010; 184(5):2518-2527. [PubMed: 20100933]

Pengal RA, Ganesan LP, Wei G, Fang H, Ostrowski MC, Tridandapani S. Lipopolysaccharide-induced production of interleukin-10 is promoted by the serine/threonine kinase Akt. Mol Immunol. 2006; 43(10):1557-1564. [PubMed: 16263172]

Polumuri SK, Toshchakov VY, Vogel SN. Role of phosphatidylinositol-3 kinase in transcriptional regulation of TLR-induced IL-12 and IL-10 by Fc gamma receptor ligation in murine macrophages. J Immunol. 2007; 179(1):236-246. [PubMed: 17579043]

Renshaw M, Rockwell J, Engleman C, Gewirtz A, Katz J, Sambhara S. Cutting edge: impaired Tolllike receptor expression and function in aging. J Immunol. 2002; 169(9):4697-4701. [PubMed: 12391175]

Rijneveld AW, Florquin S, Speelman P, Edwards CK, Dinarello CA, van der Poll T. Interleukin-1 receptor antagonist transiently impairs antibacterial defense but not survival in murine pneumococcal pneumonia. Eur Cytokine Netw. 2003; 14(4):242-245. [PubMed: 14715417] 
Romero-Steiner S, Musher DM, Cetron MS, Pais LB, Groover JE, Fiore AE, et al. Reduction in functional antibody activity against Streptococcus pneumoniae in vaccinated elderly individuals highly correlates with decreased IgG antibody avidity. Clin Infect Dis. 1999; 29(2):281-288. [PubMed: 10476727]

Saegusa K, Yotsumoto S, Kato S, Aramaki Y. Phosphatidylinositol 3-kinase-mediated regulation of IL-10 and IL-12 production in macrophages stimulated with CpG oligodeoxynucleotide. Mol Immunol. 2007; 44(6):1323-1330. [PubMed: 16824602]

Santos-Sierra S, Deshmukh SD, Kalnitski J, Kuenzi P, Wymann MP, Golenbock DT, et al. Mal connects TLR2 to PI3Kinase activation and phagocyte polarization. EMBO J. 2009; 28(14):20182027. [PubMed: 19574958]

Schwandner R, Dziarski R, Wesche H, Rothe M, Kirschning CJ. Peptidoglycan- and lipoteichoic acidinduced cell activation is mediated by toll-like receptor 2. J Biol Chem. 1999; 274(25):1740617409. [PubMed: 10364168]

Seo HS, Michalek SM, Nahm MH. Lipoteichoic acid is important in innate immune responses to gram-positive bacteria. Infect Immun. 2008; 76(1):206-213. [PubMed: 17954723]

Snapper CM, Rosas FR, Jin L, Wortham C, Kehry MR, Mond JJ. Bacterial lipoproteins may substitute for cytokines in the humoral immune response to T cell-independent type II antigens. J Immunol. 1995; 155(12):5582-5589. [PubMed: 7499841]

Stack JH, Emr SD. Vps34p required for yeast vacuolar protein sorting is a multiple specificity kinase that exhibits both protein kinase and phosphatidylinositol-specific PI 3-kinase activities. J Biol Chem. 1994; 269(50):31552-31562. [PubMed: 7989323]

Stephens L, Cooke FT, Walters R, Jackson T, Volinia S, Gout I, et al. Characterization of a phosphatidylinositol-specific phosphoinositide 3-kinase from mammalian cells. Curr Biol. 1994; 4(3):203-214. [PubMed: 7922325]

Sun K, Salmon SL, Lotz SA, Metzger DW. Interleukin-12 promotes gamma interferon-dependent neutrophil recruitment in the lung and improves protection against respiratory Streptococcus pneumoniae infection. Infect Immun. 2007; 75(3):1196-1202. [PubMed: 17210665]

Tachado SD, Li X, Swan K, Patel N, Koziel H. Constitutive activation of phosphatidylinositol 3kinase signaling pathway down-regulates TLR4-mediated tumor necrosis factor-alpha release in alveolar macrophages from asymptomatic HIV-positive persons in vitro. J Biol Chem. 2008; 283(48):33191-33198. [PubMed: 18826950]

Takeuchi O, Kawai T, Muhlradt PF, Morr M, Radolf JD, Zychlinsky A, et al. Discrimination of bacterial lipoproteins by Toll-like receptor 6. Int Immunol. 2001; 13(7):933-940. [PubMed: 11431423]

Virbasius JV, Guilherme A, Czech MP. Mouse p170 is a novel phosphatidylinositol 3-kinase containing a C2 domain. J Biol Chem. 1996; 271(23):13304-13307. [PubMed: 8663140]

Weichhart T, Costantino G, Poglitsch M, Rosner M, Zeyda M, Stuhlmeier KM, et al. The TSC-mTOR signaling pathway regulates the innate inflammatory response. Immunity. 2008; 29(4):565-577. [PubMed: 18848473]

Wetzler LM. The role of Toll-like receptor 2 in microbial disease and immunity. Vaccine. 2003; 21 Suppl 2:S55-S60. [PubMed: 12763684]

Woodgett JR, Ohashi PS. GSK3: an in-Toll-erant protein kinase? Nat Immunol. 2005; 6(8):751-752. [PubMed: 16034428]

Yoshimura A, Lien E, Ingalls RR, Tuomanen E, Dziarski R, Golenbock D. Cutting edge: recognition of Gram-positive bacterial cell wall components by the innate immune system occurs via Toll-like receptor 2. J Immunol. 1999; 163(1):1-5. [PubMed: 10384090] 

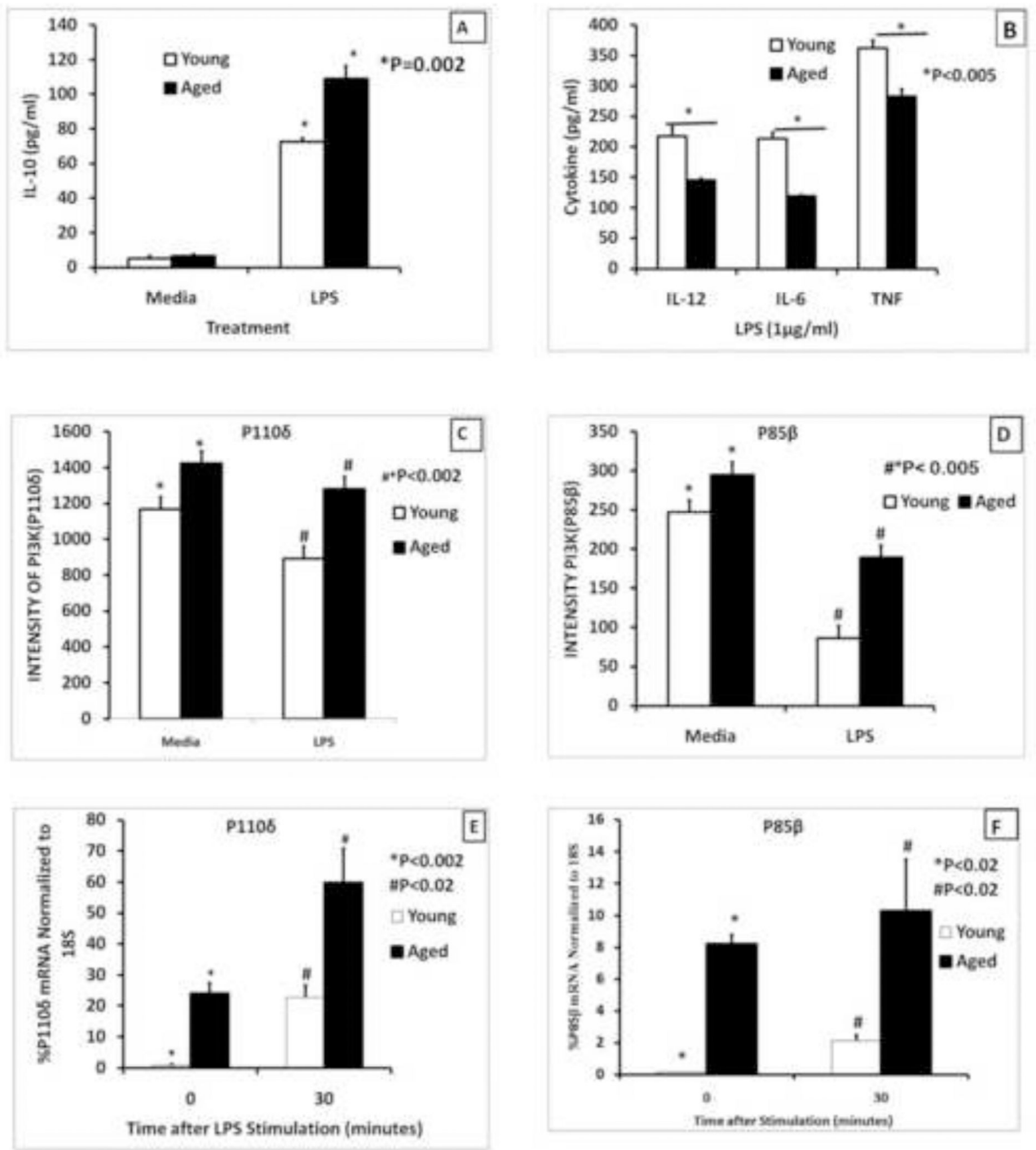

Figure 1. Age-associated changes in cytokine production and levels of PI3K subunits in splenic macrophages stimulated via TLR4

Splenic macrophages $\left(2.5 \times 10^{5}\right.$ cells $\left./ \mathrm{ml}\right)$ from young (2-4 months) and aged (20-24 months old) mice purified by negative selection using an AUTOMACS cell separator were stimulated with LPS $(1 \mu \mathrm{g} / \mathrm{ml})$ for 24 hours (Panels A and B) and the supernatants were collected and analyzed for IL-10 (Panel A) or pro-inflammatory cytokines, IL-12(p40), IL-6, and TNF- $\alpha$ (Panel B ). The results are shown as mean $+/-$ SE of duplicate determinations from triplicate cultures, and are representative of three independent experiments. The symbol * indicates the statistical significance of differences in cytokine secretion between the young and the aged. 
Panels $\mathrm{C}$ and $\mathrm{D}$ represent levels of RNA for $\mathrm{p} 110 \delta$ and $\mathrm{p} 85 \beta$ subunits derived from microarray analysis performed on gene expression in young and aged macrophages as reported in Chelvarajan et al.(R. L. Chelvarajan, et al., 2006). QRT-PCR analysis of mRNA is shown in panels $\mathrm{E}$ and $\mathrm{F}$ for $\mathrm{P} 110 \delta$ and $\mathrm{p} 85 \beta$ subunits respectively of PI3 kinase in purified splenic macrophages from young and the aged. The $C_{t}$ values for each probe were normalized to the $18 \mathrm{~S}$ RNA. The symbols $*$ and ${ }^{\#}$ indicate the statistical significance of differences in RNA expression between the young and the aged. 

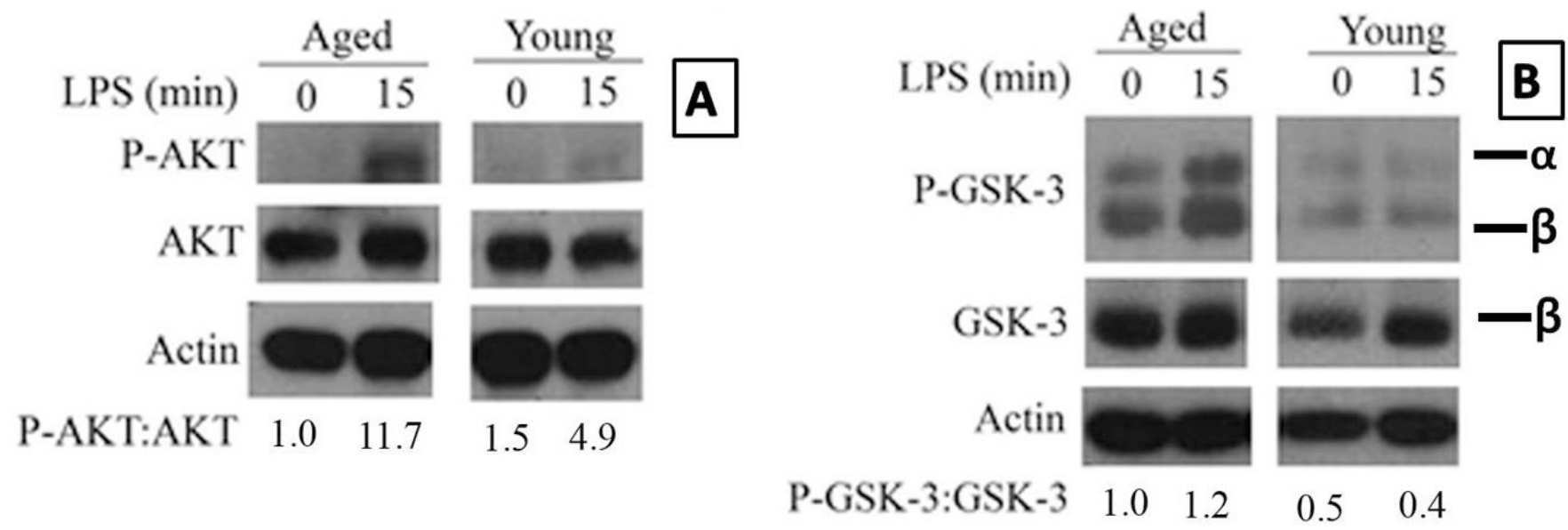

Figure 2. The age-associated increase in phosphorylation of AKT and GSK-3 in TLR-4 stimulated macrophages

Purified young adult and aged splenic macrophages were stimulated with LPS $1 \mu \mathrm{g} / \mathrm{ml}$ for 15 minutes. Panels A and B show the phosphorylation of Akt and GSK-3 respectively in the aged and the young splenic macrophages stimulated with LPS. The blots were stripped and probed for total AKT and actin in panel A and for total GSK-3 $\beta$ and actin in panel B. The numbers represent densities of bands normalized to total AKT with the values for unstimulated aged macrophages set to one.

The figure in panel $\mathrm{A}$ is a composite of blots for P-Akt, Akt and actin from the same membrane that was stripped and reprobed. The same method was employed to assemble panel B for P-GSK-3 $\alpha \beta$, GSK-3 $\beta$ and actin. The young and aged cell lysates were electrophoresed on the same gel and the membranes were exposed for identical time periods. Although a detailed kinetic analysis of LPS stimulation was performed, only the lanes representing 0 minutes and 15 minutes time points are shown for clarity. 

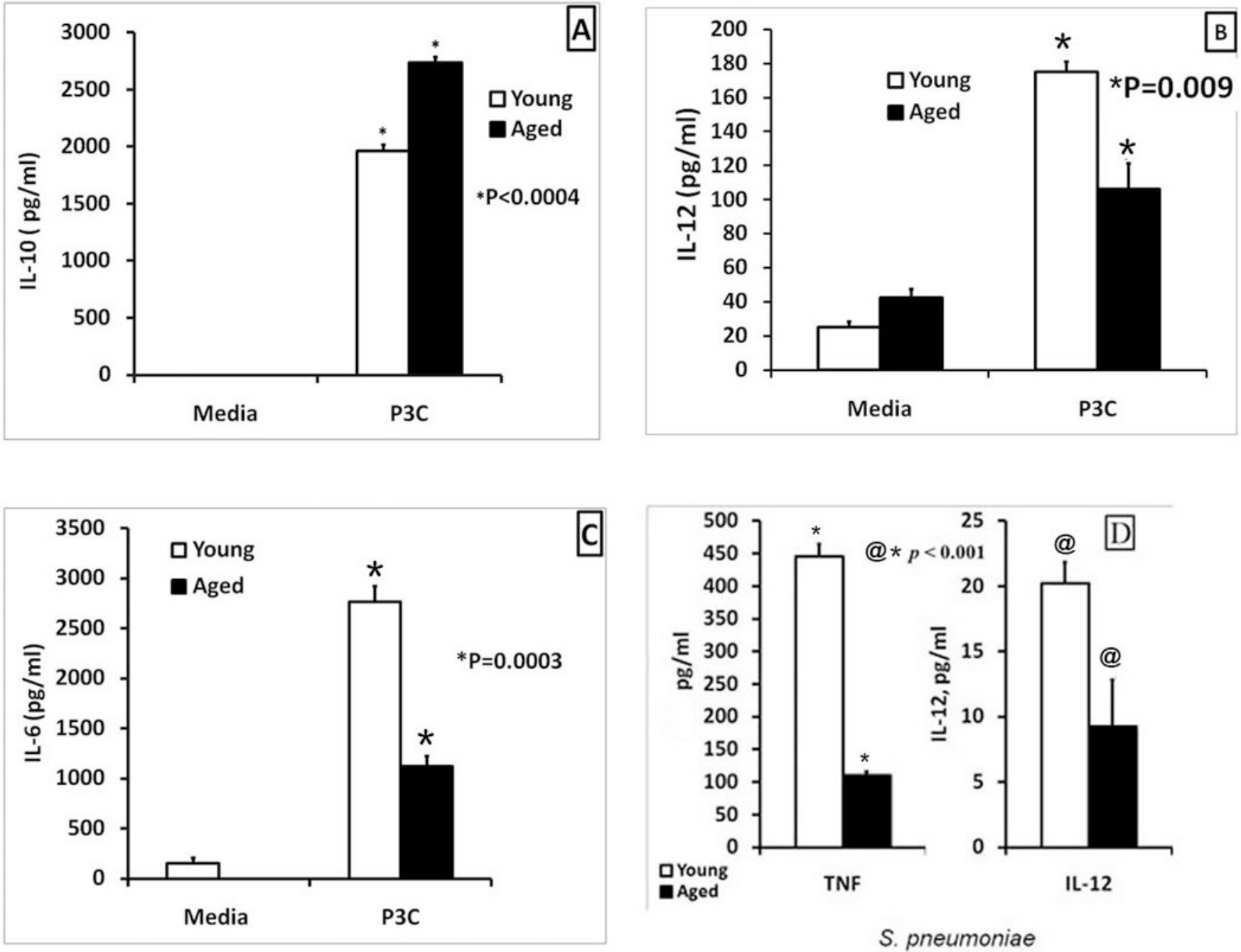

Figure 3. TLR-2 and HKSP-mediated cytokine dysregulation in young and aged splenic macrophages

Macrophages $\left(2.5 \times 10^{5}\right.$ cells $\left./ \mathrm{ml}\right)$ purified from the spleens of young and aged mice were stimulated with the TLR-2 agonists, Pam3CSK4 $(1 \mu \mathrm{g} / \mathrm{ml})$ (Panels A, B and C) or killed S. pneumoniae $\left(2 \times 10^{6} \mathrm{CFU} / \mathrm{ml}\right)$ (panel D) for 24 hours. The supernatants were collected and analyzed by a sandwich ELISA for IL-10 (Panels A), IL-12(p40) (Panels B and D), IL-6 (Panel C) and TNF- $\alpha$ (Panel D). In panel A, IL-10 levels in unstimulated young and aged macrophages were undetectable. Results from one of three experiments are shown as Mean \pm SE values of 8-12 determinations. The statistical significance of differences in cytokine secretion between the young and the aged is indicated by the symbols* and @. 

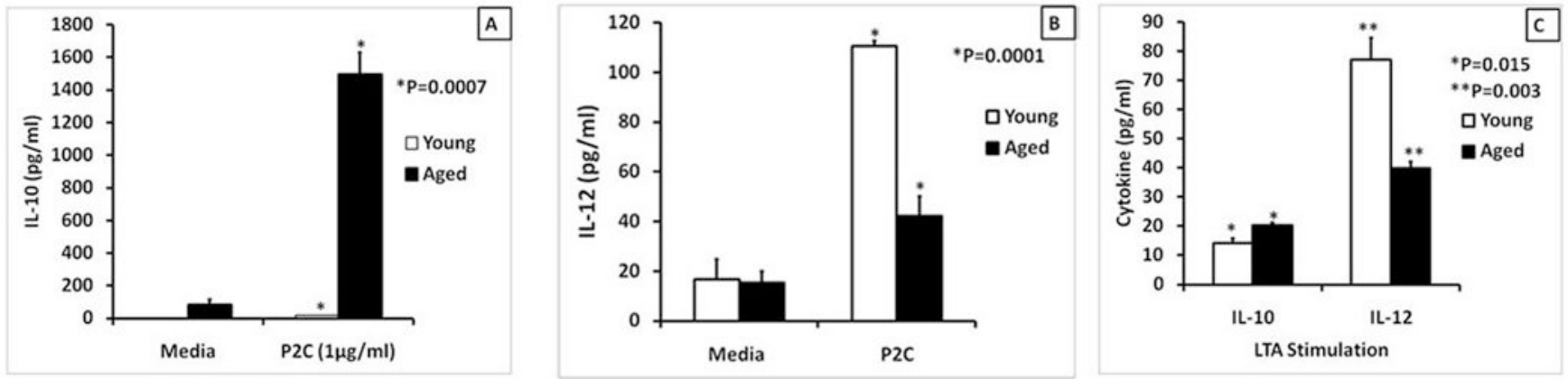

Figure 4. Age-related cytokine dysregulation in response to stimulation of macrophages with TLR2 ligands

Splenic macrophages $\left(2.5 \times 10^{5}\right.$ cells $\left./ \mathrm{ml}\right)$ from young and aged Balb/c mice purified by negative selection were stimulated with either Pam2CSK4 $(1 \mu \mathrm{g} / \mathrm{ml})($ Panels A and B) or LTA $(1 \mu \mathrm{g} / \mathrm{ml})($ Panel C). Supernatants were collected at 24 hours and analyzed for IL-10 (Panel A and C) or IL-12(p40) (Panels B and C). The results are shown as mean $+/-$ SE of duplicate determinations from triplicate cultures, and are representative of three independent experiments. The symbols $*$ and $* *$ indicate the statistical significance (Student's $\mathrm{t}$ test) of differences in cytokine secretion between the young and the aged. 

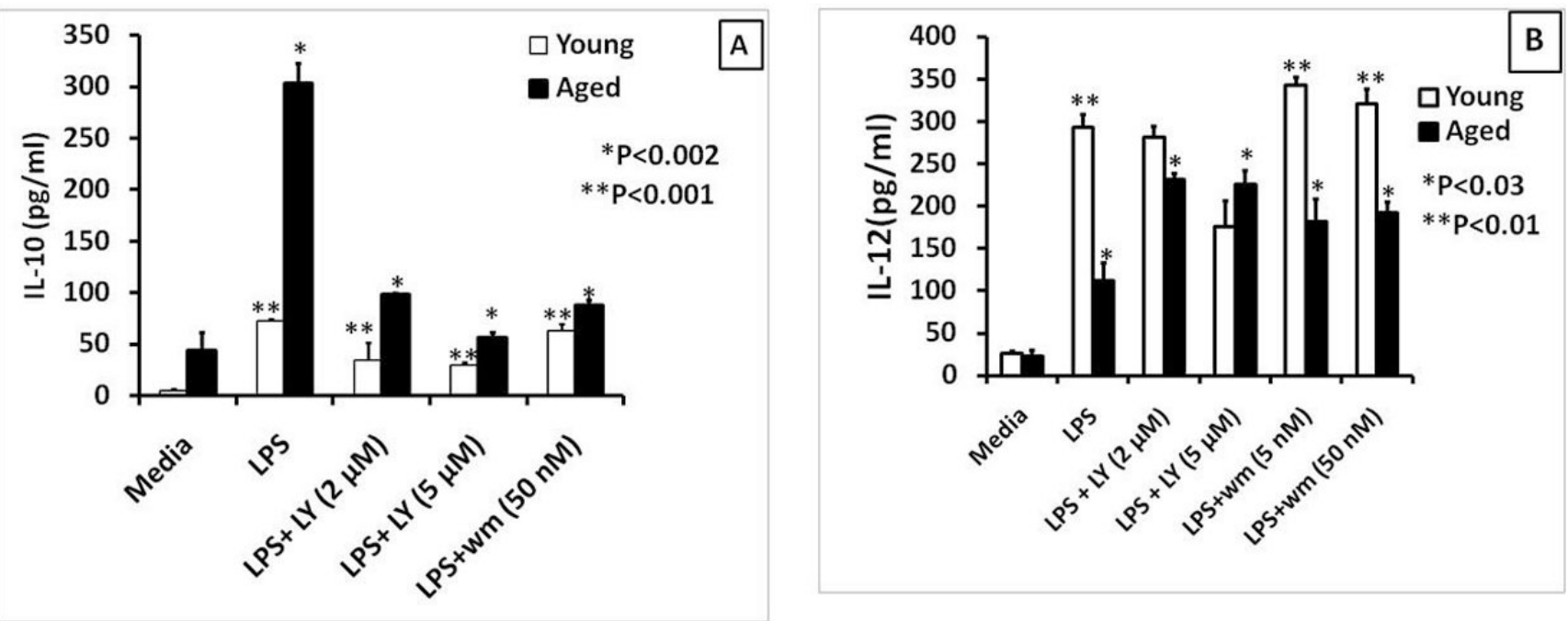

LPS (Min) $\quad 0 \quad 15 \quad 30 \quad 30 \quad 30$

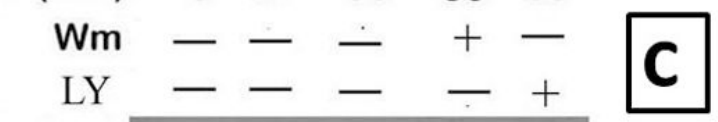

P-AKT

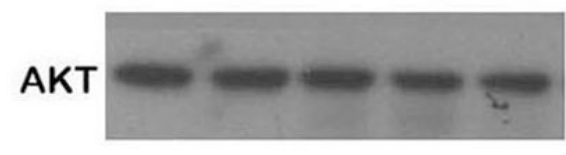

Actin

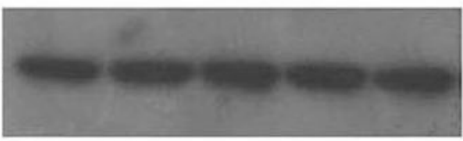

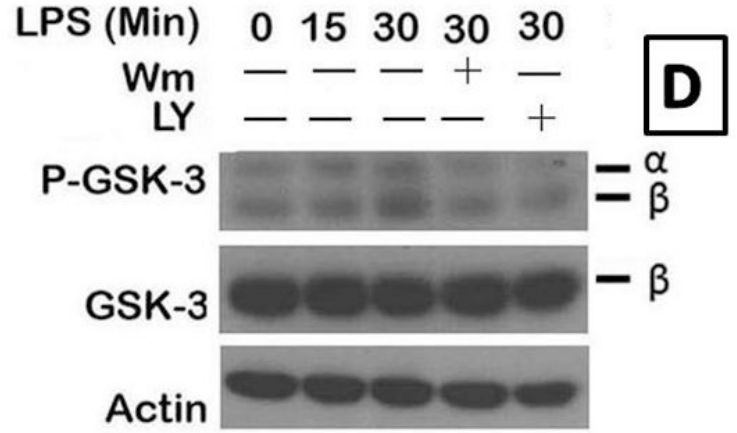

P-GSK:GSK $1.0 \quad 1.5 \quad 2.5 \quad 1.2 \quad 0.9$

P-AKT:AKT $\quad 1.0 \quad 51.0 \quad 42.5 \quad 26.7 \quad 11.5$

Figure 5. PI3K inhibitors partially rescue the age-associated defect in TLR-4 induced cytokine production by inhibiting phosphorylation of Akt and GSK-3

The graphs show cytokine secretion by purified aged and young adult splenic macrophages pretreated with either 2 or $5 \mu \mathrm{M}$ LY294002 or 5 or $50 \mathrm{nM}$ wortmannin (panels A and B) for 60 minutes and then stimulated with LPS $(1 \mu \mathrm{g} / \mathrm{ml})$ for 24 hours. Supernatants were collected and assayed for IL-10 (panel A) and IL-12 (p40) (panel B) by sandwich ELISA. Data are presented as mean+/-SE values of 6-10 determinations and are representative of three independent experiments. The symbols * and ** indicate statistical significance of differences in responses in groups treated with LPS alone compared to groups treated with LPS + PI3K inhibitor.

Purified young adult splenic macrophages were pre-treated with either LY294002 or wortmannin for 1 hour and then stimulated with LPS (Panel C) for 15 or 30 minutes. The blots were probed for $\mathrm{p}$-Akt and later probed for total Akt and actin after stripping. The numbers represent densities of bands normalized to total AKT with the values for unstimulated aged macrophages set to 1 . Panel D shows relative changes in phosphorylated GSK-3 in young splenic macrophages stimulated with LPS in the presence of PI3K 
inhibitors. The numbers represent densities of both GSK-3alpha and GSK-3beta bands normalized to total GSK-3 $\beta$ with the values for unstimulated aged macrophages set to one. Results are representative of two independent experiments.

The final figure in panel $\mathrm{C}$ is a composite of blots for P-Akt, Akt and actin for samples run on the same membrane that was stripped and reprobed. There was a lane 6 for inhibition with LY294002 at 15 minutes, but this was deleted for consistency between wortmannin and LY294002 at 30 minutes. The same method was employed to generate the Panel D; except that membrane was probed for GSK-3 instead of Akt. 

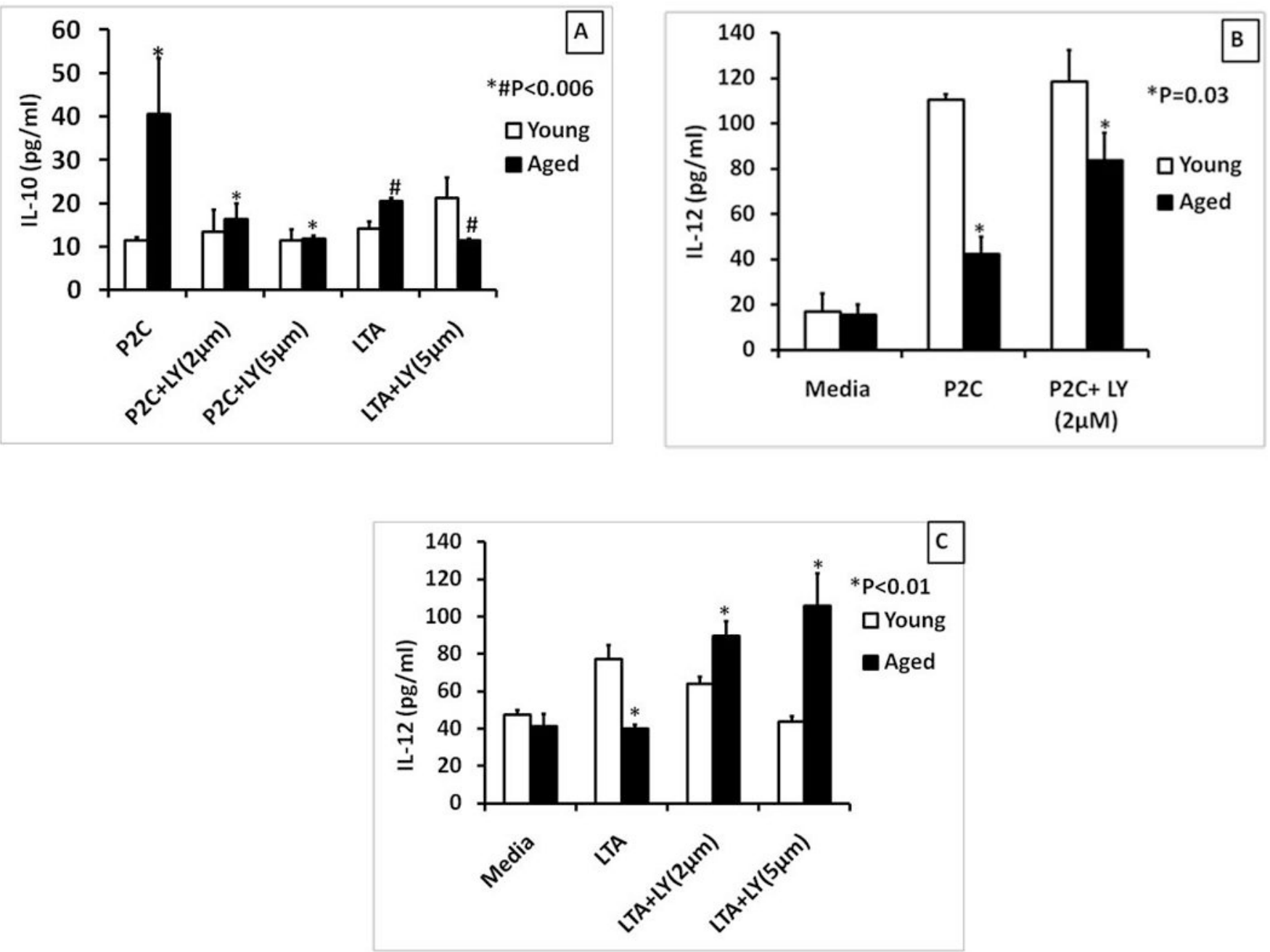

Figure 6. Cytokine dysregulation in aged splenic macrophages stimulated with TLR2 ligands can be partially rescued by inhibiting PI3K

The graphs show cytokine secretion by purified aged and young adult splenic macrophages pretreated with LY294002 for 60 minutes and then stimulated with Pam2CSK4 (Panels A and B), LTA $(1 \mu \mathrm{g} / \mathrm{ml})$ (Panels A and C) for 24 hours. Supernatants were collected and assayed for IL-10 (Panel A) or IL-12(p40) (Panels B and C) by sandwich ELISA. Data are presented as mean $+/-$ SE of duplicate cultures and duplicate ELISA's. The symbols * and \# indicate statistical significance of responses in the aged splenic macrophages treated with Pam2CSK4 or LTA with or without the PI3K inhibitor. 

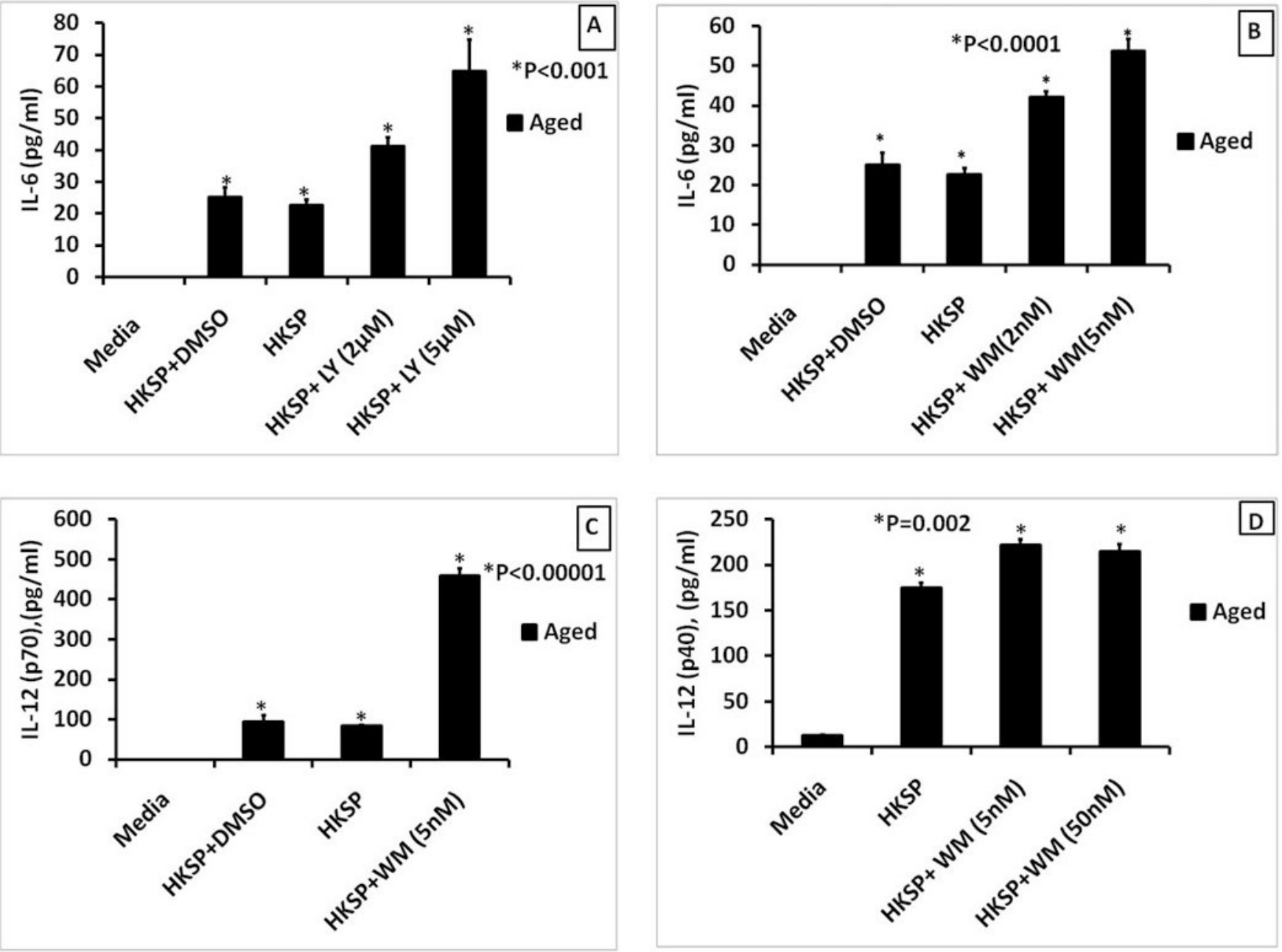

Figure 7. The inhibition of PI3K by either LY294002 or wortmannin enhanced the HKSPmediated induction of pro-inflammatory cytokines in aged splenic macrophages The graphs show cytokine secretion by purified aged splenic macrophages pretreated with LY294002 (panel A) or wortmannin (Panels B, C and D) for 60 minutes and then stimulated with HKSP $\left(2 \times 10^{8} \mathrm{CFU} / \mathrm{ml}\right)$ for 24 hours. Supernatants were collected and assayed for IL-6 (Panels A and B), IL-12(p70) (Panel C) and IL-12(p40) (Panel D) by sandwich ELISA. Data are presented as mean $+/-$ SE of duplicate cultures and duplicate ELISA's. The symbol * indicates statistical significance of responses in the aged splenic macrophages treated with HKSP alone compared to the responses obtained by treating with HKSP + PI3K inhibitor. 

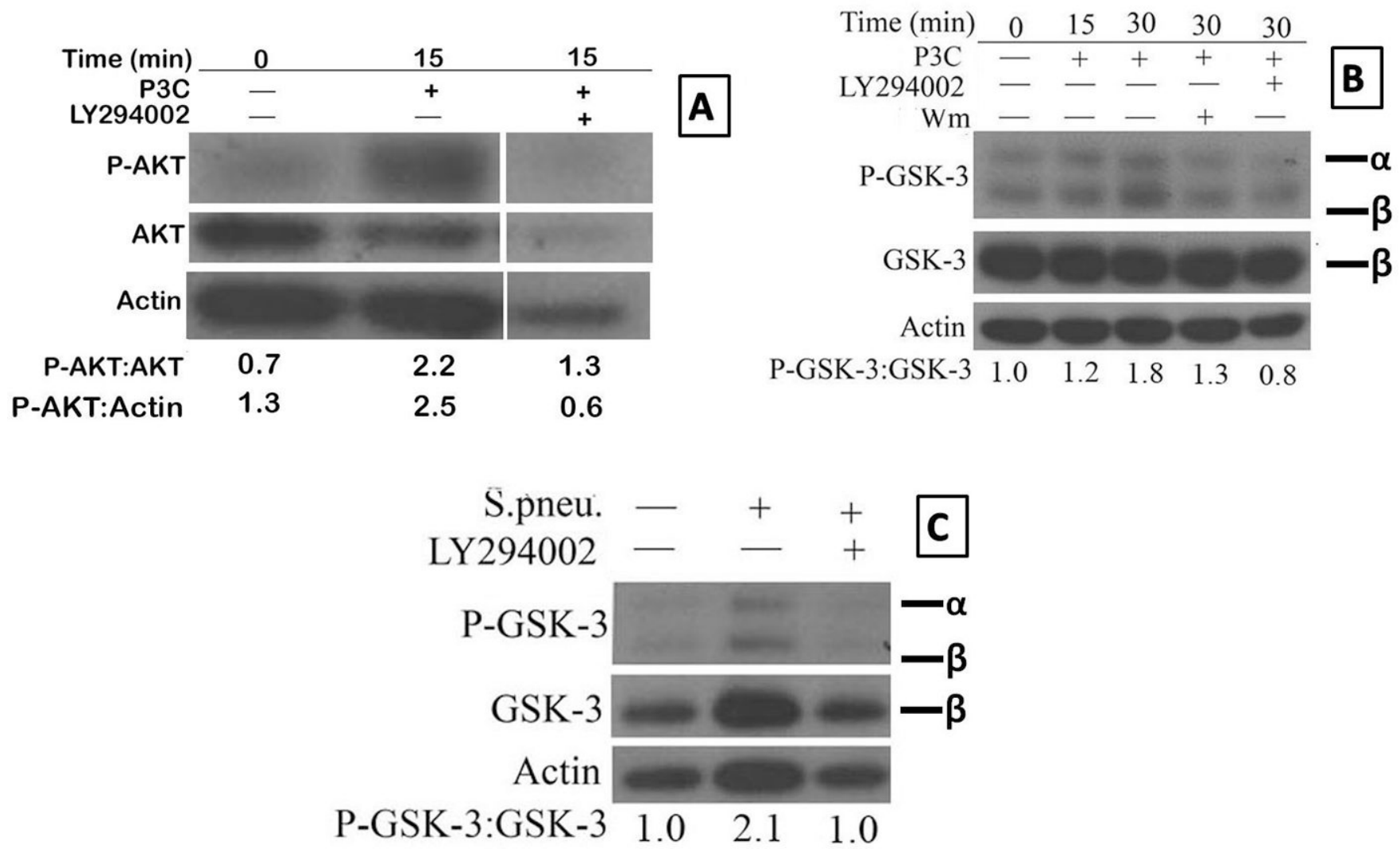

Figure 8. Age-associated cytokine defect in TLR-2 and HKSP activated macrophages is due to a defect in the AKT-GSK-3 signaling axis

Purified aged splenic macrophages were pre-treated with either LY294002 or wortmannin for 1 hour and then stimulated with Pam-3-CSK4 (Panels A and B) or HKSP $\left(2 \times 10^{8} \mathrm{CFU} /\right.$ $\mathrm{ml}$ ) (Panel C) for 15 or 30 minutes, respectively. The blots were probed for p-Akt (Panel A), p-GSK-3 $\alpha \beta$ (Panels B and C) and later probed for total Akt (Panel A), total GSK-3 $\beta$ (panels $\mathrm{B}$ and $\mathrm{C}$ ) and actin after stripping. The numbers represent densities of bands normalized to total AKT, actin or GSK-3 with the values for unstimulated aged macrophages set to 1.

Results are representative of two independent experiments.

The final figure in A is a composite of blots for P-Akt, Akt and actin for aged samples run on the same membrane that was stripped and reprobed. The intervening space (between second and third lane) was for lanes loaded with lysates from other time points or treated with other inhibitors but were deleted to focus on the effect of P3C on Akt activation at 15 minutes, which was maximum in this experiment. 

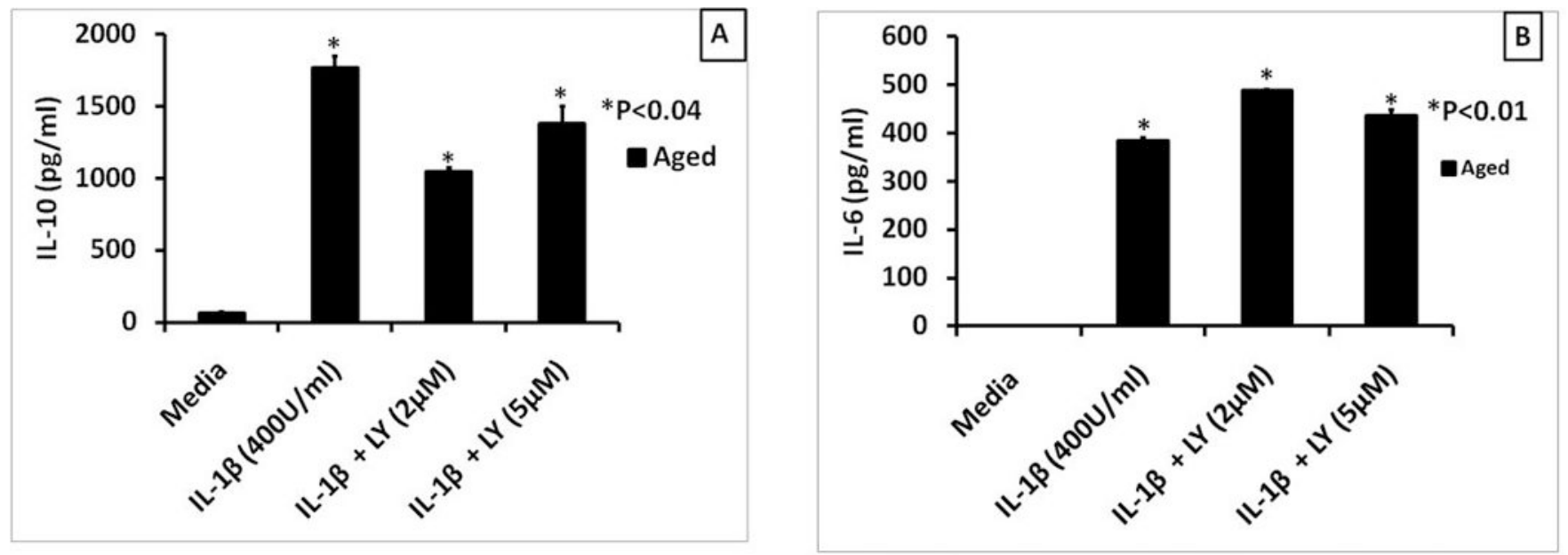

Figure 9. The effect of PI3K inhibition on IL-1 $\beta$ induced cytokine production in splenic macrophages

Panels A and B respectively show the levels of IL-10 and IL-6 secreted by IL-1 (400U/ml) stimulated aged splenic macrophages pretreated with LY294002 for 60 minutes. Supernatants were collected and assayed for IL-10 and IL- 6 by sandwich ELISA. Data represent mean $+/-$ SE of duplicate determinations of supernatants from duplicate cultures. The symbol * indicates the statistical significance of differences in cytokine levels between cells treated with IL-1 alone or IL-1 + the PI3K inhibitor. 